\title{
ALTOS DE REVEQUE: UN ASENTAMIENTO FORTIFICADO FENICIO-PÚNICO EN EL LITORAL DE ANDALUCÍA ORIENTAL ${ }^{1}$

\author{
ALTOS DE REVEQUE: A FORTIFIED PHOENICIAN \\ PUNIC SETTLEMENT ON THE COAST OF EASTERN \\ ANDALUSIA
}

\author{
JOSÉ LUIS LÓPEZ CASTRO \\ FRANCISCO MANZANO-AGUGLIARO \\ BELÉN ALEMÁN OCHOTORENA
}

\begin{abstract}
RESUMEN
Se presentan los primeros datos sobre un nuevo asentamiento fortificado próximo al litoral occidental de la provincia de Almería, en el sureste de la Península Ibérica. Se analiza el sistema de muralla de casamatas, así como los materiales arqueológicos superficiales que permiten datar su funcionamiento entre la segunda mitad del siglo vi a. C. y finales del siglo v o principios del IV a. C. Se propone una funcionalidad relacionada con el control estratégico de recursos mineros y agrícolas por parte de la antigua ciudad fenicia de Abdera.
\end{abstract}

\section{SUMMARY}

We report preliminary results from research into a new fortified settlement located close to the western coast in the current province of Almería in the Southeast of the Iberian Peninsula. An analysis is made of the fortification system, consisting of a casemate walls, and of the archaeological materials collected at the surface, offering a chronology of the site between the second half of the $6^{\text {th }}$ century B.C. to the end of the $5^{\text {th }}$ or early $4^{\text {th }}$ century B.C. The function proposed for the site is that of a strategic control of metal and agricultural resources by the ancient Phoenician city of Abdera.

PALABRAS CLAVE: Territorio de las ciudades fenicias occidentales, explotación de recursos minerales y agrícolas, muralla de casamatas.

KEYWORDS: Western Phoenician town territory, exploitation of metal and agricultural resources, casemates wall.

En este trabajo presentamos los primeros resultados que ha ofrecido el estudio preliminar de este

\footnotetext{
${ }^{1}$ Este trabajo es resultado del Proyecto de Excelencia P06HUM-01827 El patrimonio fenicio en el litoral oriental andaluz. Investigación, puesta en valor y difusión, financiado por la Consejería de Innovación, Ciencia y Empresa de la Junta de Andalucía.
}

nuevo yacimiento arqueológico, efectuado gracias al encargo de la Delegación de la Consejería de Cultura de la Junta de Andalucía a un equipo de investigadores de la Universidad de Almería, para la elaboración del expediente de declaración como Bien de Interés Cultural. Altos de Reveque fue descubierto casualmente en la primavera de 2008 por D. Ramón Alférez Peralta, técnico de los servicios de Cultura del Ayuntamiento de El Ejido, miembro de la asociación de defensa del Patrimonio Histórico Athena, y ejemplo de actividad incansable y desinteresada en la protección y difusión del patrimonio histórico del Poniente almeriense.

El levantamiento topográfico se realizo con equipos GPS bifrecuencia (5800 de Trimble) en modo relativo o diferencial con medida de fase en tiempo real, también conocido como RTK (Real Time Kinematic) o cinemático. El modo RTK implica que uno de los receptores, denominado estación base, se encuentra en posición conocida y transmite correcciones diferenciales vía radio al otro receptor, equipo móvil, que realiza el levantamiento obteniendo precisión centimétrica. ${ }^{2}$

Aunque el modo RTK obtenga el levantamiento con precisión centimétrica, éste puede estar desplazado, es decir, tener problemas de georreferenciación, o lo que es lo mismo, que sufra un desplazamiento respecto de la cartografía oficial del lugar, UTM huso 30 norte en nuestro caso. Este problema se resolvió procesando a su vez, en modo relativo, la estación

\footnotetext{
${ }^{2}$ Manzano-Agugliaro F. y Montero Rodríguez M.A 2004:
} 
base GPS situada en el Reveque con otra estación base GPS fija. En nuestro caso se empleó la estación base de Almería de la RAP (Red Andaluza de Posicionamiento), que sirve a través de Internet ${ }^{3}$ de forma gratuita correcciones diferenciales de modo continuo, existiendo un total de 22 estaciones en Andalucía. Con esto último se georreferencia la estación base situada dentro del perímetro amurallado de nuestro trabajo con precisión centimétrica, ya que el tiempo de observación es de varias horas. A este último método de posicionamiento se le denomina modo relativo con medida de fase en postproceso, y es el método empleado para levantar las redes geodésicas.

Además, para tener un control de cada una de las 6 sesiones de trabajo con GPS realizadas en días diferentes, se tomaron también dos puntos de referencia fijos en cada sesión, a fin de comprobar que los distintos levantamientos de campo encajaban sin desplazamiento. Dichos puntos son dos hitos permanentes de hormigón que se sitúan en la cima de la colina oriental de Altos de Reveque. Para el levantamiento topográfico se realizó un modelo digital del terreno con cerca de 3000 puntos abarcando todo el recinto y un contorno exterior mínimo de 25 metros, a partir del cual se generó un plano topográfico con una equidistancia entre curvas de nivel de 0,5 metros. Para ello se transformaron las alturas elipsoidales obtenidas con el GPS en alturas ortométricas (altura sobre el nivel del mar) mediante un modelo de geoide, el IGG2005. ${ }^{4}$

En el levantamiento de las construcciones, dado el gran volumen de datos recogido, se realizó una codificación de cada punto levantado, para asegurar así su correspondencia con cada entidad identificada en el campo. La planimetría que se presenta reúne las construcciones que se aprecian visualmente en la superficie del yacimiento, en la medida en que los derrumbes y la vegetación permitían tomar los datos durante el trabajo de campo.

Se procedió también a efectuar una prospección superficial del asentamiento y las alturas adyacentes, llevando a cabo una recogida selectiva del material arqueológico observable en superficie, así como de diversas muestras de mineral que fueron analizadas mediante Difracción de Rayos X. El material cerá-

\footnotetext{
3 R.A.P. http://www.juntadeandalucia.es/obraspublicasytransportes/redandaluzadeposicionamiento/rap/

${ }^{4}$ Corchete V.; Chourak M.; Khattach D. 2005. No obstante, para clarificar la representación de las estructuras del recinto fortificado, en las figuras del presente artículo se ha simplificado el plano topográfico aumentando la equidistancia de curvas a 5 metros.
}

mico fue dibujado y clasificado y se presenta también un estudio del mismo.

El yacimiento arqueológico de Altos de Reveque ha estado completamente inédito hasta su descubrimiento en 2008. No se puede, en principio, relacionar con ningún topónimo de las fuentes clásicas y no ha sido nunca objeto de estudio alguno. Por su carácter excepcional tampoco contamos con sitios similares que hayan sido estudiados y publicados. Por todo ello, y dado que tampoco se han efectuado excavaciones arqueológicas, los únicos elementos disponibles para su identificación, interpretación histórica y datación son el análisis constructivo, tipológico y comparativo de la planta del recinto amurallado, el análisis de las cerámicas y otras muestras recogidas en superficie, así como la valoración del contexto histórico en que se desenvolvió el asentamiento. En consecuencia, la interpretación que proponemos de Altos de Reveque debe entenderse con las cautelas propias de un estudio sobre un asentamiento que aún debe aportar mucha información arqueológica una vez se obtengan datos de excavación más concluyentes.

\section{EL ASENTAMIENTO Y SU ENTORNO}

El yacimiento de Altos de Reveque se sitúa en las estribaciones meridionales de la Sierra de Gádor, formando parte del complejo denominado La Sierrecilla, en el área suroccidental del término municipal de Dalías, en la Baja Alpujarra almeriense (Fig. 1). La Sierra de Gádor es un sistema montañoso situado en la parte suroccidental de la provincia de Almería, que limita con la de Granada y se dispone muy próxima al litoral. Con una altitud media elevada, de unos 1000 metros, y un relieve muy accidentado, la Sierra de Gádor está constituida geológicamente por materiales del Triásico que se pueden agrupar en dos tipos principales de formaciones: una primera de filitas y cuarcitas y una segunda de calizas margosas y dolomías. Sometida a fenómenos volcánicos, la Sierra de Gádor presenta una notable riqueza mineral, principalmente plomo, así como hierro, cobre y plata, asociada en ocasiones al plomo. ${ }^{5}$

Desde la Antigüedad los importantes recursos mineros de la Sierra de Gádor fueron intensamente explotados, como atestiguan diversos indicios, sobe todo de época romana, así como en época medieval y moderna. ${ }^{6}$ En el siglo xIX se intensificó la produc-

5 Maestre 1844: 155; Artero García 1986; Sánchez Hita 2007:43; Pérez de Perceval 1989: 22

${ }^{6}$ Cara; Rodríguez 1986; Domergue 1987: 3 ss.; 1990: 203, 414; Cara 2002; Cara y Vázquez 2008. 


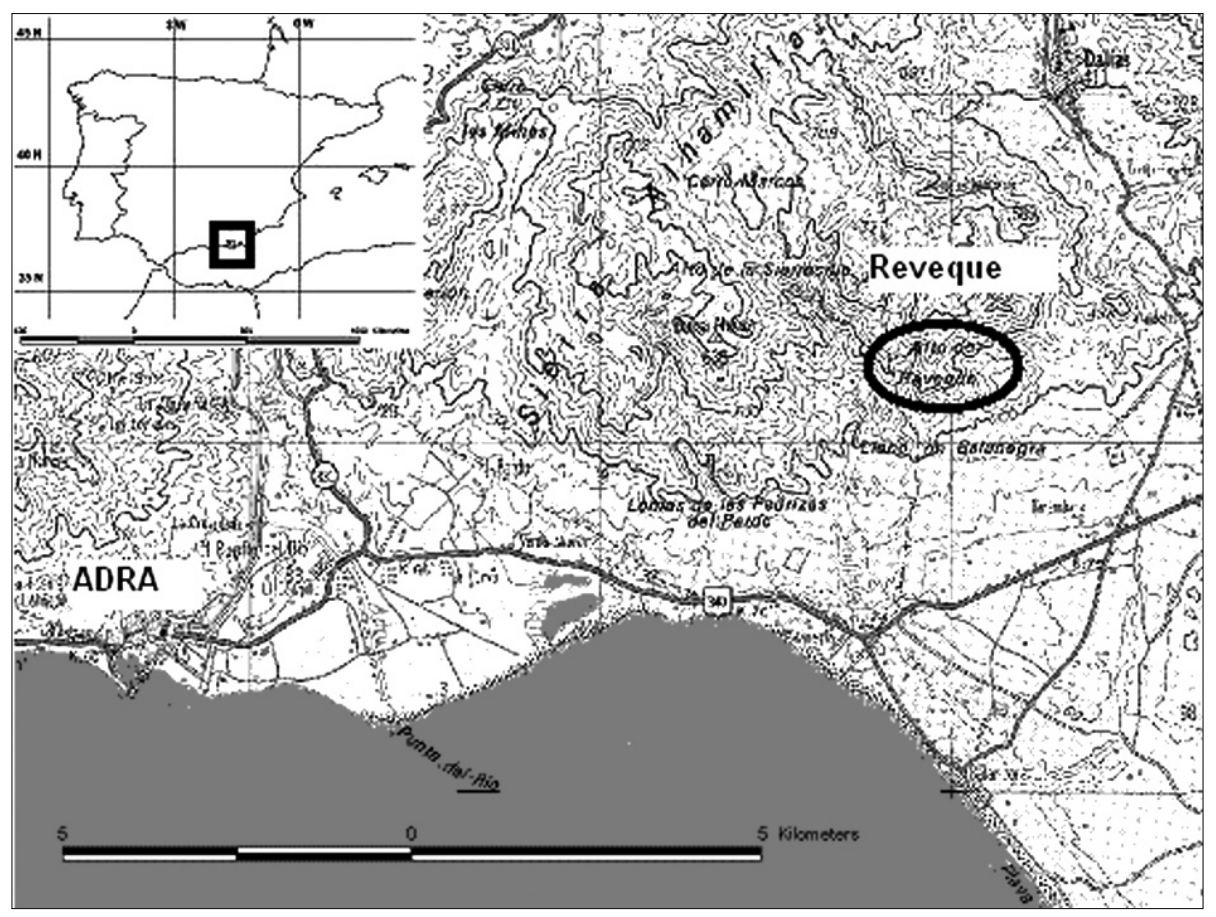

Figura 1. Mapa de localización de Altos de Reveque (E/ 1: 50.000).

ción minera en la zona, sobre todo de plomo, constituyendo entonces la más importante de España. A pesar de que mayoritariamente los plomos de la Sierra de Gádor tenían un contenido bajo en plata, ya en el siglo XIX los estudiosos de la minería advirtieron la presencia de criaderos de plata con un alto contenido en este metal, en áreas asociadas a pórfidos de la Sierra de Gádor, en concreto en áreas de Enix, Vícar y Dalías, y recogieron algunos testimonios arqueológicos de la explotación de los recursos mineros en la Antigüedad. ${ }^{7}$

El municipio de Dalías concentraba en su término numerosas minas y boliches, hornos de tipo artesanal para el beneficio de metales como el plomo, situados junto a los puntos de extracción de mineral, en un número mucho mayor que los demás distritos mineros de la Sierra de Gádor. ${ }^{8}$ Las ruinas de una de estas instalaciones mineras se sitúan justo al pie de los Altos de Reveque en su ladera sur. Es posible, aunque no tenemos la seguridad, de que se correspondan con el boliche al que Madoz hizo referencia en su Diccionario, con el nombre de Rebeque. ${ }^{9}$

\footnotetext{
7 Álvarez 1851: 418; Maestre 1844: 154-155, 157, 160.

${ }^{8}$ Pérez de Perceval 1984: Tabla VI, 102, 107.

${ }^{9}$ Madoz 1845-1850: 354.
}

Al pie de la ladera, junto a las ruinas del boliche, se encuentra un nacimiento de agua cuya existencia debió sin duda condicionar favorablemente la elección del sitio para el emplazamiento de un asentamiento humano. Los Altos de Reveque son dos colinas separadas por una vaguada por la cual discurre una pequeña torrentera o arroyo donde circula el agua con ocasión de las lluvias. La formación geológica de la colina más oriental, dolomías tableadas afectadas por procesos clásticos, motivó la existencia de diaclasas y la circulación de agua subterránea, cuyos indicios son apreciables en algunas de las nueve cavidades naturales existentes en esta colina. ${ }^{10}$

Con una altitud máxima de 389,5 metros, el yacimiento goza de una visibilidad privilegiada al este, sur y suroeste, que alcanza sobre el mar casi todo el Golfo de Almería y buena parte de la costa del Poniente almeriense, desde el Cabo de Gata hasta las Albuferas de Adra (Fig. 2). También domina visualmente el antiguo Campo de Dalías, una extensa área cultivable hoy día perteneciente en buena parte al municipio de El Ejido y cubierta de invernaderos. Hacia el noreste, norte y oeste el yacimiento obtiene una visibilidad más limitada, dirigida hacia las alturas de la Sierra de Gádor.

\footnotetext{
${ }^{10}$ Contreras; García 2008.
} 


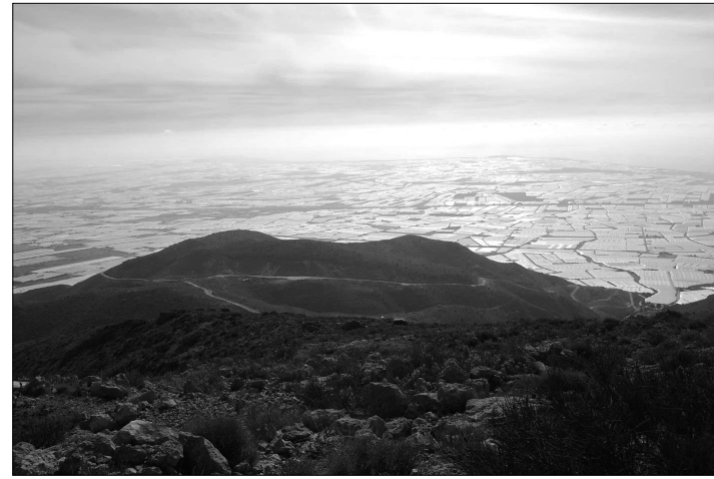

Figura 2. Vista del yacimiento desde el norte.

Desde los Altos de Reveque se divisa en primer término hacia el noreste el Cerrón de Dalías, un oppidum ibero del que dista dos kilómetros y que pensamos podría identificarse con la antigua Murgi. ${ }^{11}$ Aunque no ha sido excavado, los materiales superficiales atestiguan para el Cerrón una larga secuencia de ocupación desde la Prehistoria, reconociéndose en superficie varias edificaciones y un sistema defensivo formado por dos murallas concéntricas, aunque no sabemos si serían contemporáneas entre sí. ${ }^{12}$

El asentamiento de Altos de Reveque consiste en un recinto amurallado con un perímetro de 1057 metros y una superficie de 5,3 hectáreas (Fig. 3). Emplea técnicas constructivas similares en toda su extensión y seguramente debió ser planificado y construido de una sola vez, según parecen indicar las estructuras constructivas, la concepción del espacio protegido y la funcionalidad militar y estratégica del asentamiento. El interior del recinto está ocupado sólo parcialmente por pocos edificios exentos y distantes entre sí que no componen una aglomeración urbana, si bien parece haber una mayor concentración de edificios al sur, donde la superficie es más llana y permite la edificación con más facilidad. La mayor parte del área fortificada presenta en superficie el sustrato rocoso o una fina cobertera vegetal sin que se reconozcan sedimentos arqueológicos fuera de las áreas donde hay edificaciones. La bajísima densidad de materiales arqueológicos en superficie y su concentración en las áreas próximas a la muralla y a los edificios, da idea también de la reducida ocupación humana de que fue objeto el recinto, pues a pesar de que los procesos erosivos han debido actuar en la cuenca de las torrenteras, la orografía no permite la edificación sin emplear sistemas de aterrazamiento que se emplearon en la construcción de algunos edificios como puede obser-

\footnotetext{
${ }^{11}$ Para las fuentes sobre Murgi vid. Roldán 2006: 654.

12 Cara 1999: 119-128.
}

varse, y que sin embargo no se aprecian en laderas que conservan su perfil natural, pues de haber existido habrían dejado una evidente impronta a pesar de la erosión, así como algún material cerámico erosionado que está totalmente ausente.

El amurallamiento de una gran extensión de terreno, superior a las 5 hectáreas responde pues, posiblemente, a planteamientos tácticos y poliorcéticos. Los objetivos serían los de no dejar sin protección ninguno de los dos altos o colinas paralelas cuya similar altitud - 389,5 m la occidental y $384 \mathrm{~m}$ la oriental- podría dejar expuesta una fortificación de inferior extensión a merced de hipotéticos atacantes desde la otra altura vecina.

El recinto amurallado se adapta completamente a la naturaleza del terreno, sobre todo en las áreas más accidentadas y escarpadas. La posición dominante del asentamiento fortificado y la gran envergadura de la muralla, así como la naturaleza rocosa del terreno justifican la inexistencia de un foso que circundase parcialmente el recinto, del que no se han localizado superficialmente indicios de ninguna clase.

La muralla (Fig. 4) es continua salvo en dos tramos, uno en el ángulo noroeste del recinto, donde se sitúa un cortijo moderno en ruinas que empleó en su edificación piedras de la muralla destruyendo unos 35 metros de la misma, y otro tramo en el lado sur, precisamente donde el barranco o arroyo que separa las dos colinas se abre al vacío. En ambos tramos se pierde la muralla sin que se distinga en la superficie rocosa traza alguna de su continuidad. En el ángulo suroeste del recinto se edificó un gran aprisco o corral para el ganado empleando también piedras de las construcciones antiguas, lo que hace que no se reconozca con seguridad en superficie, el trazado de unos 28 metros de muralla, aunque es posible que se conserve alguna hilada debajo de los derrumbes.

\section{EL SISTEMA DE FORTIFICACIÓN}

La muralla de Altos de Reveque es de una gran complejidad y en los lados norte, oeste y sur está construido mediante la técnica de doble paramento con compartimentos interiores, efectuados mediante muros perpendiculares dispuestos a intervalos regulares (Fig. 4). Este sistema defensivo también recibe el nombre de muralla de casamatas. ${ }^{13}$ Los dos muros paralelos que componen la muralla presentan una anchura igual en todo el trazado: en torno a 1

${ }^{13}$ Una discusión sobre el uso inapropiado del término en Montanero 2008: 96 


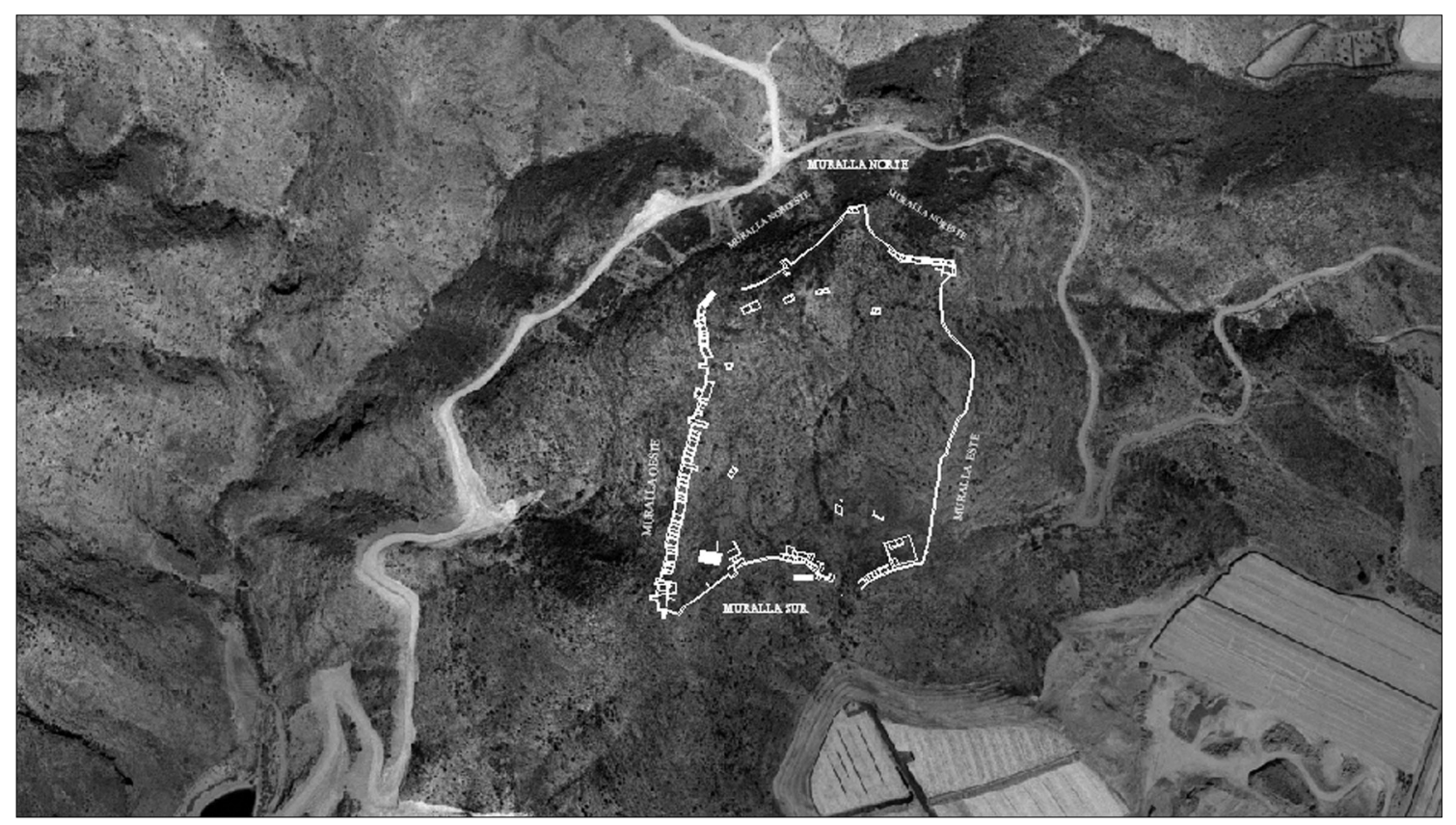

Figura 3. Ortofotografía aérea con superposición de la planimetría (E/ 1: 10.000).

metro el paramento exterior y sobre $0,50-0,52$ metros el interior. Estas dimensiones pueden relacionarse con los sistemas metrológicos empleados por fenicios y cartagineses, que aunque no fueron unívocos en el tiempo y en el espacio, se basaban en unidades como el codo babilonio de $50-51 \mathrm{~cm}$, el codo egipcio de $52,3 \mathrm{~cm}$ o el codo fenicio de $49,7 \mathrm{~cm}$, empleados en las fortificaciones de Motya, así como el codo de $51,87 \mathrm{~cm}$ utilizado en Cartago en el siglo v a. C. ${ }^{14}$

Teniendo en cuenta la disgregación sufrida en las piedras de las murallas de Altos de Reveque y la pérdida de argamasas, revestimientos y enlucidos, podemos tomar como referencia un codo feniciopúnico de unos $52 \mathrm{~cm}$, medida que se aproxima más a las obtenidas en la mayoría de los muros del asentamiento y que está en la línea de las unidades metrológicas antes mencionadas. Así pues, el ancho del paramento exterior sería de unos dos codos, mientras que la anchura del interior y de los tirantes perpendiculares que formaban los compartimentos interiores sería de un codo.

Sin embargo, la anchura total de la muralla, es decir, la distancia entre el muro exterior y el interior es diferente en cada tramo: en la muralla noreste la anchura total es de unos 6,20 m., aproximadamente 12 codos; en la muralla oeste varia en su progresión

\footnotetext{
${ }^{14}$ Barresi 2007: 20-21
}

al sur entre los 5,5 y los 8,5 metros aproximadamente, es decir, entre los 11 y los 17 codos, mientras que en la muralla sur la anchura es similar a la del paño noreste. Esta diferencia se debe posiblemente a las necesidades defensivas, pues la máxima anchura coincide con la ladera más accesible, la oeste, y por tanto la más vulnerable, por lo que quizás se reforzó dotándola de un mayor grosor. De hecho, en la ladera este, al ser casi inaccesible, los constructores juzgaron suficiente levantar un solo muro, de idéntica anchura que el exterior en los demás lienzos, un codo.

De igual modo, la distancia entre los tirantes interiores de la muralla que generan los compartimentos interiores difiere de unos tramos a otros, con separaciones de unos 2 metros, o 4 codos, en la norte y sur y unos 3 metros o 6 codos en la muralla oeste. Los cambios de trazado y los ángulos en la muralla a lo largo del perímetro generan compartimentos interiores más irregulares.

La unidad de construcción y de concepto de la fortificación queda patente en algunos puntos de la muralla oeste, donde se comprueba cómo el muro exterior y los tirantes están trabados en la misma fábrica, lo que indica que no se adosaron con posterioridad, sino que se construyeron al mismo tiempo los muros exterior e interior y los tirantes. La técnica constructiva empleada es la mampostería con blo- 


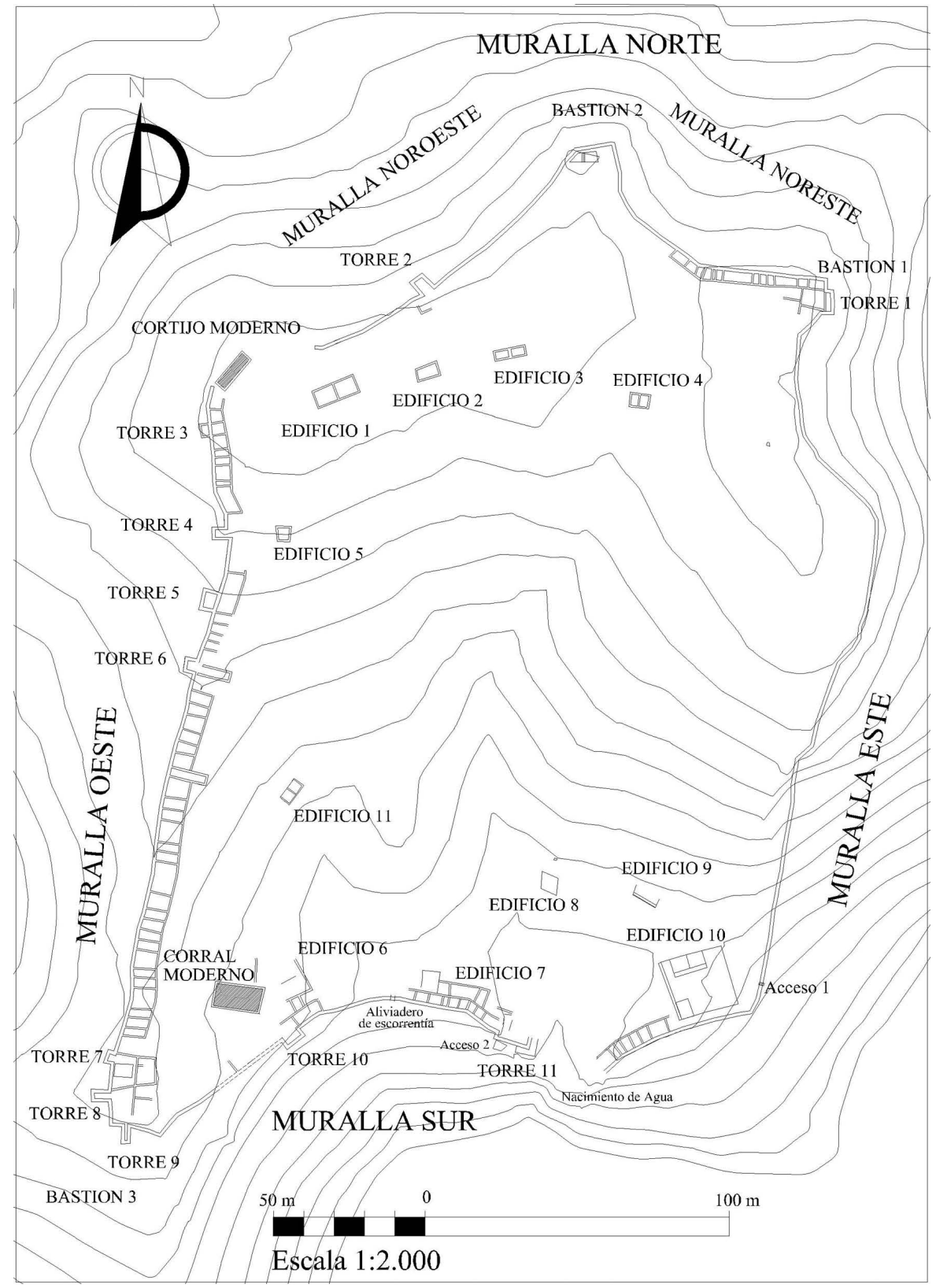

Figura 4. Planimetría de Altos de Reveque (E/ 1: 2.000, equidistancia de curvas de nivel 5 metros).

ques irregulares de piedra caliza de mediano tamaño (Fig. 5). En diversos puntos del perímetro exterior, y sobre todo en la muralla oeste, se observa con claridad la disposición de un zócalo de piedra sobre la roca que sobresale unos 30 centímetros bajo la base de la muralla. Su objeto era el de dar mayor solidez a la obra, a fin de que el muro exterior de la muralla se erigiese sobre una base sólida.
En general se conservan apenas unas pocas hiladas de alzado, aunque en algunos cortos tramos, como en el paño situado entre las torres 3 y 4 , se aprecia la conservación de una mayor altura en alzado, hasta aproximadamente 1,40 metros. Dichos alzados permiten conocer cómo los exteriores de la muralla debieron estar bien careados y emplearon ripios para regularizar el aspecto final nivelando las hiladas. No 


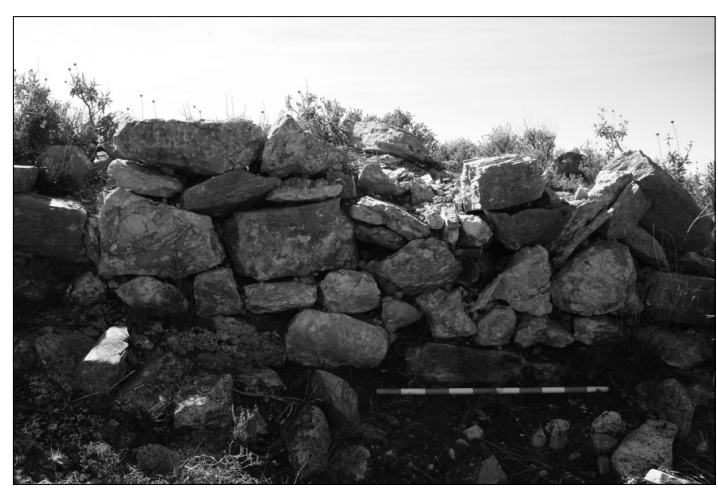

Figura 5. Alzado del paramento exterior de la muralla, al noreste.

obstante, es posible que, al igual que muchas de las murallas fenicias y cartaginesas, la fábrica de piedra alcanzase sólo una parte del alzado total de la muralla, completándose el resto con fábrica de adobes. Este extremo no podría comprobarse sino mediante información obtenida en excavación, ya que en superficie no se han conservado restos de adobes.

Bajo la muralla sur, justo donde termina un pequeño arroyo, la muralla está perforada en la base por un aliviadero bajo la fábrica de mampuesto, a fin de permitir la evacuación de la escorrentía de las aguas pluviales. Igualmente, en el extremo este de la muralla sur, coincidiendo con el barranco que evacuaría las aguas pluviales se aprecia la interrupción de la muralla, debido a que tal vez se dejó deliberadamente abierta por los ocupantes del asentamiento para facilitar la salida de aguas. Esta posibilidad se ve reforzada por la disposición de la torre 11 que cierra el trazado de la muralla.

La mayor parte de los ángulos del recinto amurallado se concibieron para reforzar las defensas flanqueando los paños de muralla para actuar como grandes torres avanzadas que aunque se aproximan al concepto de baluarte, en tanto que obra de defensa situada en el encuentro de dos cortinas de muralla y saliente de los mismos, podemos denominarlos mejor como bastiones angulares.

El denominado bastión 1 se sitúa en el ángulo noreste del recinto y sirve de unión entre la muralla noreste de compartimentos interiores y la muralla este, formada por un único muro. En la cara este del bastión la muralla se adelanta unos metros sobre la línea perpendicular de la muralla noreste, formando una torre que flanquea la muralla este, denominada torre 1 (Fig. 6). Al interior del bastión 1 se disponen muros de un codo de anchura, adosados a los compartimentos interiores de la muralla, dando lugar a habitaciones y espacios compartimentados.

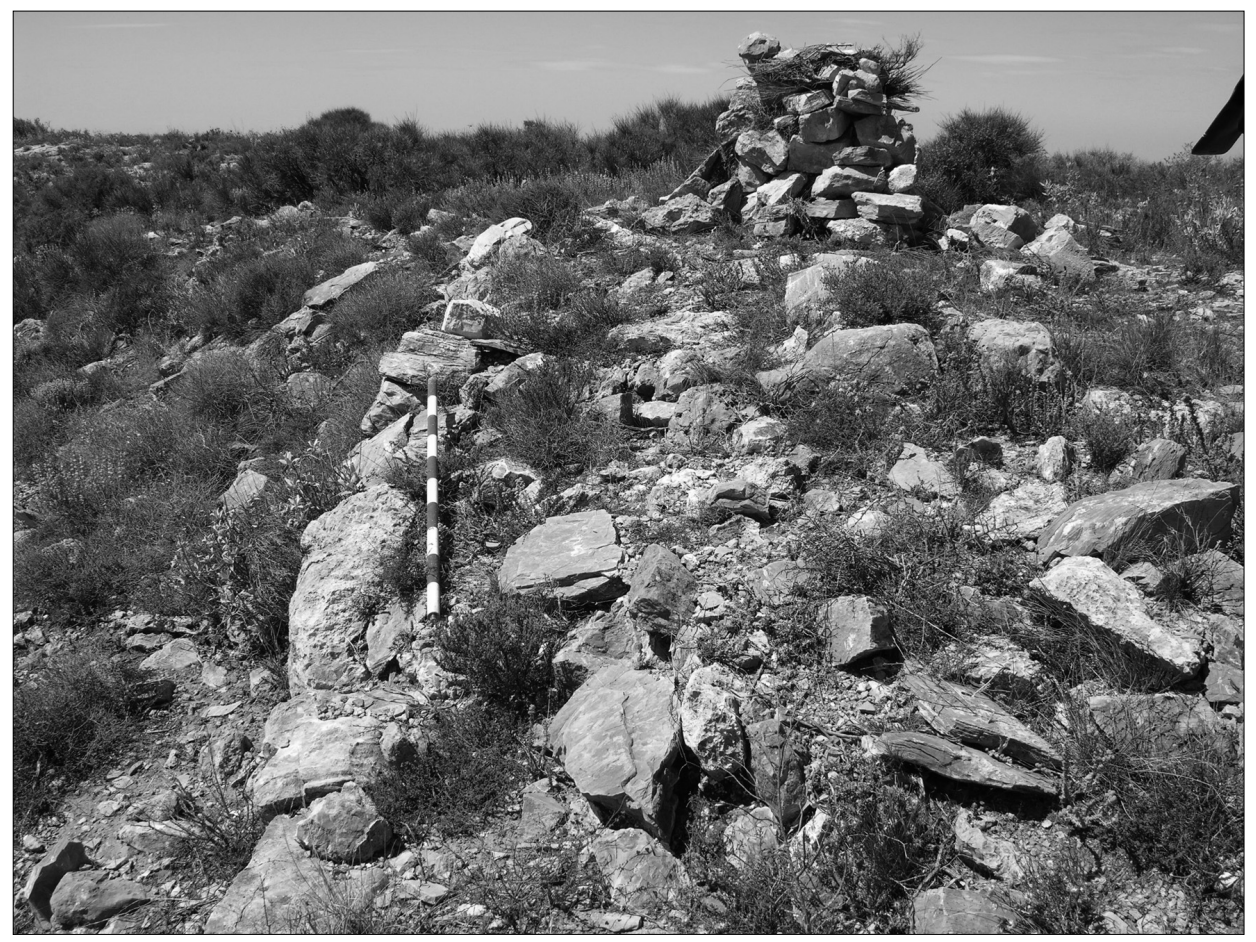

Figura 6. Vista de la torre 1 del bastión angular 1. 


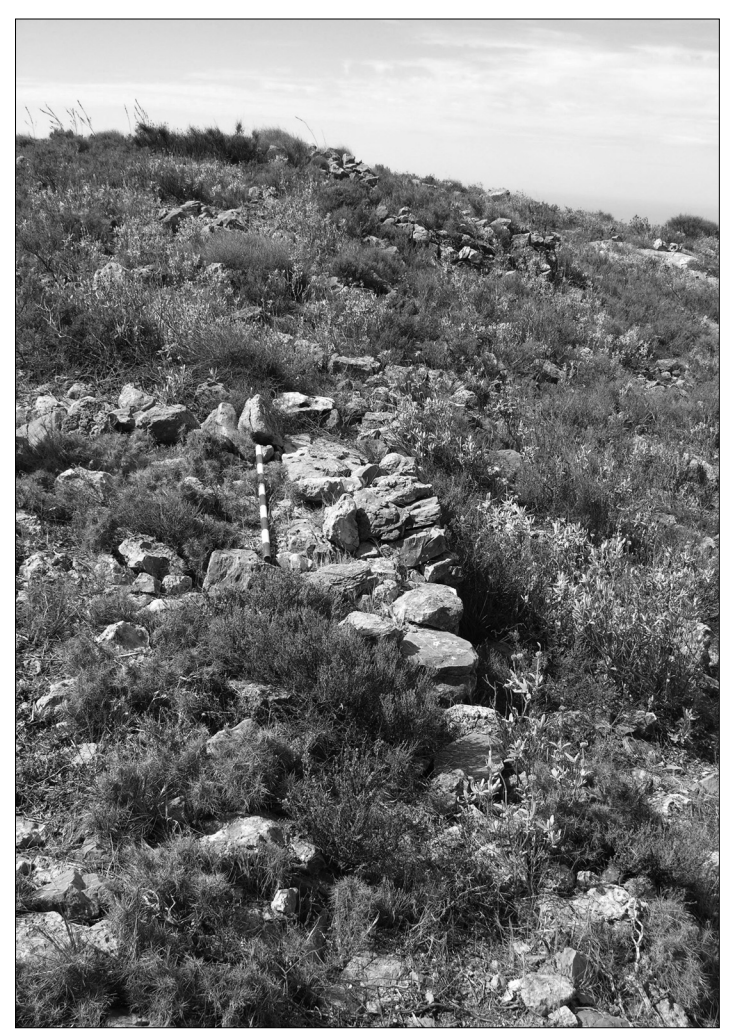

Figura 7. Paño de la muralla noroeste; al fondo la torre 2.

El bastión angular 2 se sitúa en el extremo norte de la muralla de esta orientación. El cierre poligonal es en sí mismo un refuerzo que flanquea la muralla noroeste con la torre 2 y la muralla noreste con el bastión 1 para cruzar el lanzamiento de proyectiles a hipotéticos asaltantes sin dejar ángulos muertos en las defensas. Al interior del bastión 2 se dispone una estructura maciza poligonal, aparentemente compartimentada por muros interiores que quizás sirvió como punto elevado dentro del bastión y refuerzo del mismo o como plataforma de máquinas de proyectiles.

El bastión 3, situado en el ángulo suroccidental del recinto es el más complejo de los tres, debido a que se encuentra en el área de más baja cota de la ladera oeste, la más vulnerable de la fortaleza. Su cara oeste está reforzada con dos torres, $\mathrm{n}^{\mathrm{o}} 7$ y 8 y la sur, con otra torre, la $\mathrm{n}^{\circ}$ 9. Al igual que en el bastión 1, al interior se detectan muros correspondientes a una red interna de estancias cuya funcionalidad y planta completa desconocemos. Por su situación, cabe pensar la posibilidad de que hubiese existido otro bastión angular bajo el cortijo moderno, pero no es posible confirmarlo con los datos que se aprecian en

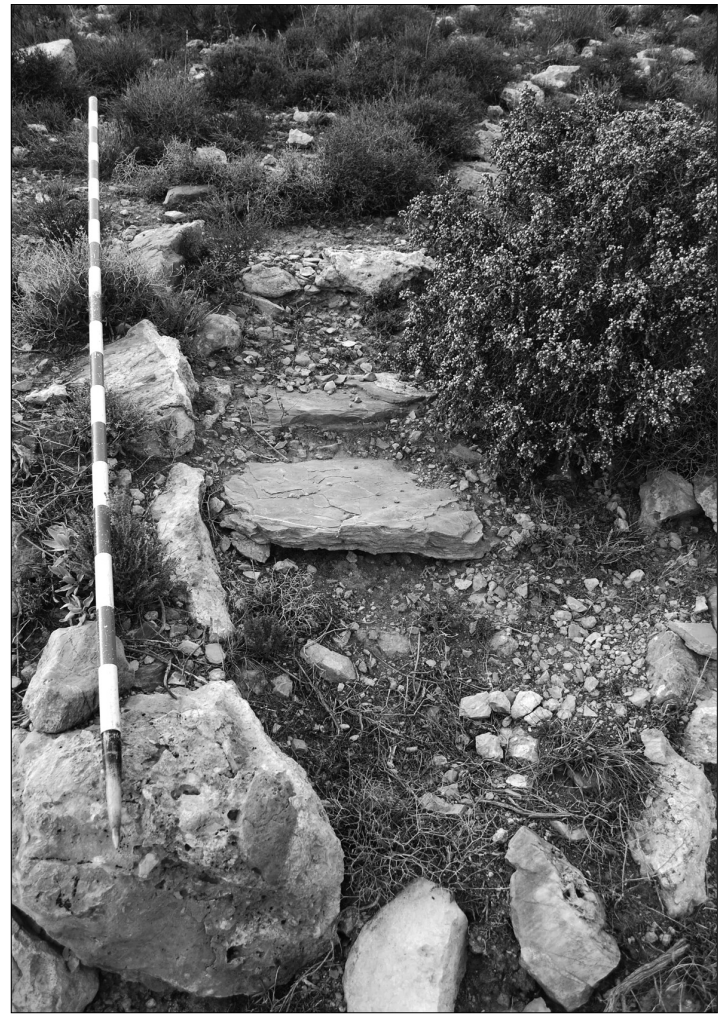

Figura 8. Acceso 1: poterna.

superficie, debido a la destrucción de la muralla a consecuencia de la construcción de aquél.

En total se han identificado once torres. La torre $\mathrm{n}^{\circ} 1$ se sitúa en la muralla noreste, dentro del bastión 1 para proteger la parte superior de la ladera oriental del recinto. La torre $\mathrm{n}^{\circ} 2$ flanquea el largo lienzo de la muralla noroeste con el bastión $\mathrm{n}^{\mathrm{o}} 2$ (Fig. 7 ), sobresale de la muralla en unos $5 \mathrm{~m}$. con unas dimensiones de unos $6.5 \times 5.3 \mathrm{~m}(12,5 \times 10$ codos $)$. Las torres $\mathrm{n}^{\circ} 3,4,5$ y 6 se emplazan en la muralla oeste, que cubre la ladera más accesible y vulnerable del recinto fortificado, distanciándose entre sí unos 14 metros. Sin embargo, después de la torre $n^{\circ}$ 6 no se observan indicios de otras torres que pudieron haber existido. Suelen adelantarse unos 4 o 5 metros de la línea de muralla con dimensiones variables en cada caso, que oscilan entre una superficie exterior de $7 \times 5$ metros en las más grandes, como la torre 5 , hasta los $4 \times 3$ metros de la torre 3 .

La torre $n^{\circ} 10$ flanquea el tramo de la muralla sur entre las torres 9 y 11 . Ésta cierra la muralla sur junto a la salida del arroyo por la muralla y cubre el vecino acceso 2, una galería excavada en la roca cuya salida se sitúa en la base de la muralla sur. Está poco 


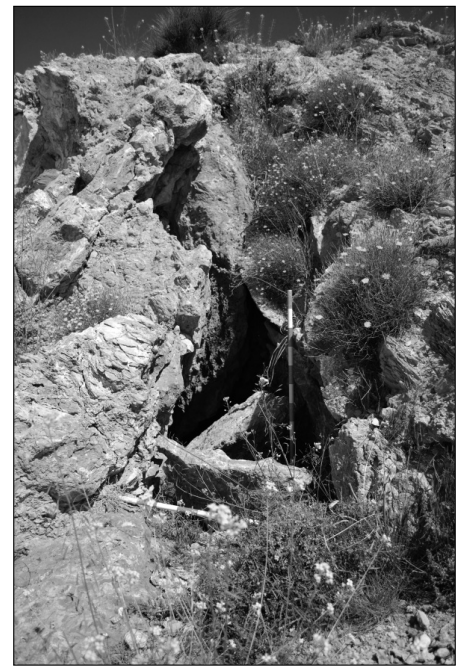

Figura 9. Acceso 2: entrada a la galería.

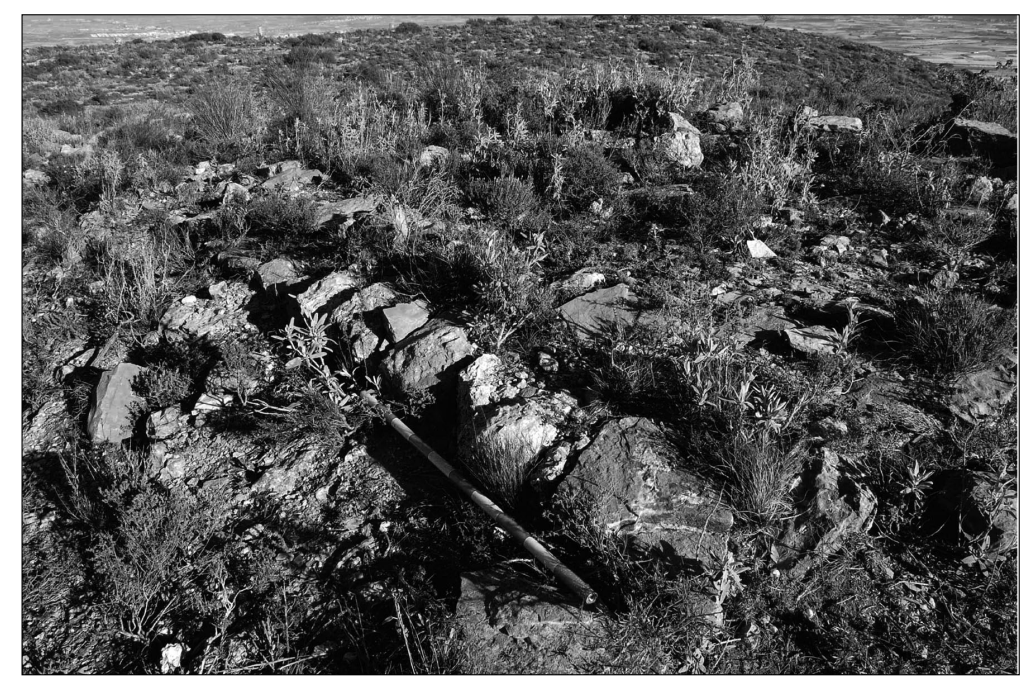

Figura 10. Edificio 3. adelantada debido a la orografía, pues el desnivel de la ladera es muy acusado en esa zona.

\section{LOS ACCESOS AL RECINTO Y LOS EDIFICIOS INTERIORES}

Por el momento se desconoce la ubicación de los accesos principales, aunque podríamos avanzar alguna hipótesis sobre su posible localización, al tiempo que se han identificado dos accesos secundarios, denominados acceso 1 y acceso 2 . El primero se sitúa en la muralla sureste, cerca del edificio 10: se trata de una poterna o postigo formado por una abertura en la muralla delimitada por lajas de piedra perpendiculares a la misma de aproximadamente un metro de anchura, que salva el desnivel hacia el exterior mediante tres escalones hechos con lajas de piedra (Fig. 8).

El acceso 2 (Fig. 9) es una galería artificial que comunica el exterior del recinto con el pie de la muralla sur, junto a la torre 11, construida seguramente para proteger y vigilar el acceso a dicha galería. Ésta se encuentra parcialmente cegada y en el suelo de la boca superior, junto a la muralla, se pueden observar grandes lajas planas de piedra que tal vez formaron el techo artificial de la salida de la galería, de donde posiblemente se desprendieron.

Los accesos principales al recinto no se aprecian con claridad en superficie, aunque hay algunos indicios para proponer una situación hipotética: una posibilidad es que se situasen en la ladera oeste, próximos a la torre $n^{\circ} 6$, en cuyo interior se emplazó un compartimento interior de mayor longitud que los demás. Es posible que se tratase de un acceso junto a la torre, prolongada al interior para cubrir la hipotética apertura de la muralla, en un sistema de protección cuyo concepto recuerda en alguna medida los accesos protegidos de Gezer o Hazor de época de Salomón, entre otros ejemplos, con puertas de cámaras o portales sucesivos que se prolongaban al interior de la muralla denominadas passage gates. ${ }^{15} \mathrm{Un}$ compartimento interior también prolongado dentro del recinto y de las mismas dimensiones que el asociado a la torre $\mathrm{n}^{\circ} 6$ se encuentra también en el mismo paño de muralla, unos 30 metros más al sur, aunque sin asociar a torre alguna. Otra posibilidad sería que el acceso principal se efectuase por el ángulo noroeste, donde se interrumpe la muralla y se encuentra el cortijo moderno. No obstante, sólo una excavación arqueológica permitiría detectar la situación de los accesos principales que con seguridad debieron existir.

En total se han podido reconocer once edificios o grupos de edificaciones en el interior del recinto. Salvo algunas construcciones que se sitúan próximas a la ladera oeste, los edificios se concentran en las áreas norte y sur del recinto amurallado, donde el terreno está más nivelado y permite una mayor amplitud para la edificación.

Las dimensiones de los edificios son de $15 \times 6,5$ metros en el caso del mayor, el $\mathrm{n}^{\circ} 1$, hasta los $6,5 \times$ 6 metros del edificio 4 o los 4 x 5 metros del más pequeño, el $n^{\circ} 5$, en el área norte. Aquí, los edificios 1 a 4 son de planta rectangular (Fig. 10) y a excepción del $\mathrm{n}^{\mathrm{o}} 2$, que sólo consta de un espacio único,

\footnotetext{
${ }^{15}$ Wright 1985: 192-193, figs. 88, 94, 103
} 
están compartimentados en dos habitaciones de igual superficie por un muro medianero. La fábrica de las hiladas de piedra que permiten reconocer la planta es de mampostería de piedras medianas y pequeñas, excepto en el edificio 4, cuyos muros son de piedras de gran tamaño.

En el área sur del recinto se concentran dos áreas de habitaciones con plantas más complejas que en el área norte, en las que no siempre es posible reconstruir las edificaciones con datos superficiales. El denominado edificio 6 se sitúa bajo el corral de ganado moderno y presenta dos niveles de cota, debido posiblemente a que se emplearon sistemas de aterrazamiento para construir en el desnivel, al igual que el edificio 11. El edificio 7, al igual que el $n^{\circ} 6$ está formado por un complejo de muros que se adosan a la muralla dando lugar al menos a cuatro habitaciones distintas. Los edificios 8 y 9 están levantados en áreas de pendiente y los restos conservados parecen corresponder a plataformas macizadas de mampostería, cuya funcionalidad no podemos determinar.

El denominado edificio 10 (Fig. 4) se sitúa en el ángulo sureste del recinto amurallado, haciendo coincidir sus vértices. Este edificio consta de una gran plataforma cuadrangular de mampostería macizada y presenta una estructura interna compleja, con distintas compartimentaciones interiores. Sus dimensiones son de $20 \mathrm{~m}$ en cada lado y una superficie total de unos $400 \mathrm{~m}^{2}$. Presenta muros adosados o que compartimentan espacios, algunos de los cuales llegan a tener 1,40 $\mathrm{m}$ de anchura. Se distinguen claramente dos de los compartimentos interiores en la parte norte del edificio, con unas dimensiones de $20 \mathrm{~m}^{2}$ y $24 \mathrm{~m}^{2}$. Por su situación junto a la muralla y su factura, así como por su proximidad con el acceso 1, la poterna abierta en la muralla, que se abre a una zona accesible al recinto por el sureste, podríamos ponerla en relación con el sistema defensivo, cumpliendo un papel de refuerzo del mismo, al igual que los bastiones angulares, aunque no es posible comprobarlo sin datos de excavación.

\section{LOS MATERIALES ARQUEOLÓGICOS}

La cronología del asentamiento nos viene indicada por los materiales cerámicos recogidos en superficie, principalmente fragmentos de ánforas, platos, cuencos, fuentes y algunas cerámicas de cocina. Los fragmentos cerámicos presentan bordes de fractura limpios y no se observan materiales rodados. Espacialmente se concentran en las áreas amuralladas, sobre todo en la ladera oeste, así como en el área de edificios situada al sur.
Las cerámicas presentan dos fábricas, una más cuidada con pastas en tonos marrones en ánforas, platos y cuencos y otra más tosca, en tono anaranjado con desgrasantes de mayor tamaño, con la que se fabricaron fuentes y cerámicas de cocina. ${ }^{16}$

El conjunto cerámico más antiguo es el formado por varios fragmentos de ánforas tipo Ramón 10.1.2.1, en concreto tres bordes (Fig. 11: a, b, c) y un fondo (Fig. 11: d), que pueden datarse como muy tarde hacia mediados o a principios de la segunda mitad del siglo vi a. C. ${ }^{17}$

Sin embargo, la mayor parte del material cerámico documentado, consistente principalmente en fragmentos de ánforas fenicio-púnicas tipo Ramón 11.2.1.3 (Fig. 11: e-k) destinadas al transporte de salazones de pescado, nos podría marcar la cronología central del uso del recinto fortificado en el siglo $\mathrm{v}$ a. C. Este tipo de ánforas se comenzó a fabricar en los alfares de Gadir hacia finales del siglo vi a. C. y continuaron distribuyéndose a lo largo del v a. C. En otras ciudades fenicias como Abdera o Baria su presencia se documenta desde los inicios del siglo v a. C. y también se produjeron en estos alfares locales. ${ }^{18}$

La fase final del asentamiento podría estar determinada por un fragmento de ánfora también fenicia (Fig. 11: 1) que podríamos identificar quizás con el tipo 11.2.1.4, una variante de las ánforas 11.2.1.3 empleada también para el almacenamiento y transporte de salazones de pescado, cuya cronología se prolonga hasta comienzos del siglo IV a. C. ${ }^{19}$ El conjunto anfórico se completa con un lote de asas de ánforas fenicias cuya adscripción podría hacerse a cualquiera de los tipos anfóricos mencionados, de las que presentamos aquí algunos ejemplares (Fig. 12: a-d).

Entre las cerámicas de cocina y comunes tenemos, en primer lugar, tres fragmentos de ollas facturados a mano (Fig. 12: e-g) que vendrían a corroborar esta cronología que se inicia a mediados del siglo vi a. C. y continúa en el v a. C., ateniéndonos a la perduración de las cerámicas a mano en las secuencias estratigráficas de Abdera y Baria. ${ }^{20}$

Con idénticas funciones y a veces con restos de combustión en su superficie, se recogieron fragmentos de tres bordes de ollas a torno de pasta grosera, con borde ligeramente engrosado y exvasado y paredes de

${ }^{16}$ Se están efectuando análisis de pastas cerámicas de Altos de Reveque por Difracción de Rayos X para compararlas con las producciones abderitanas.

17 Ramón 1995: 230-231

${ }^{18}$ Ramón 1995: 235; Ramón y otros 2007: 115 ss.; López Castro 2005; López Castro 2007: 31.

${ }^{19}$ Ramón 1995: 236

${ }^{20}$ López Castro; Alcaraz; Santos 2009: (Fig. 3: e); López Castro y otros 2009: (Fig. 6: a-b). 

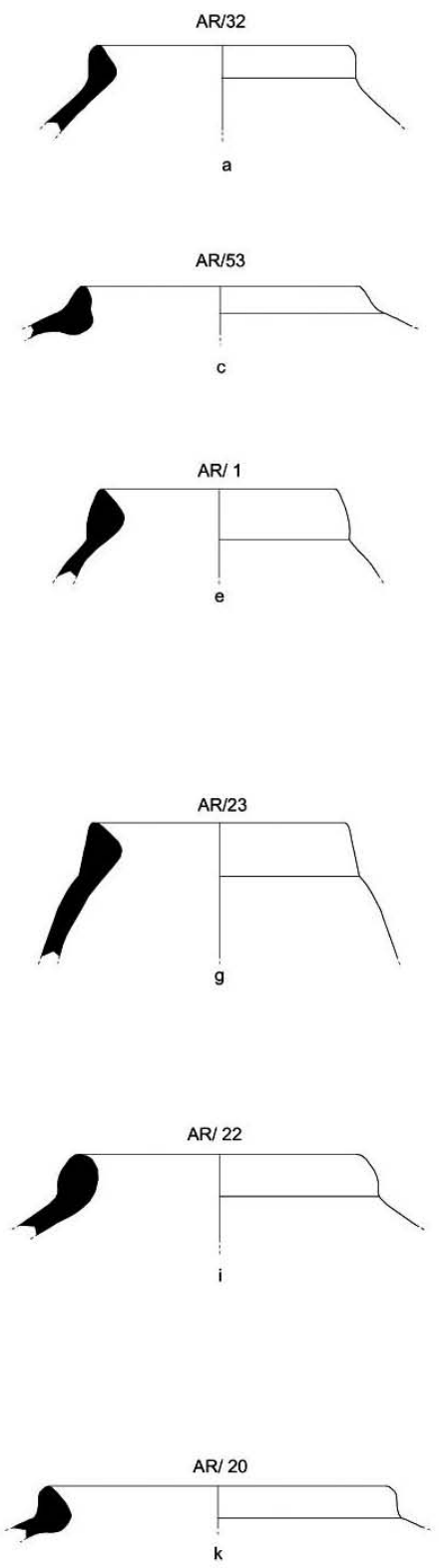
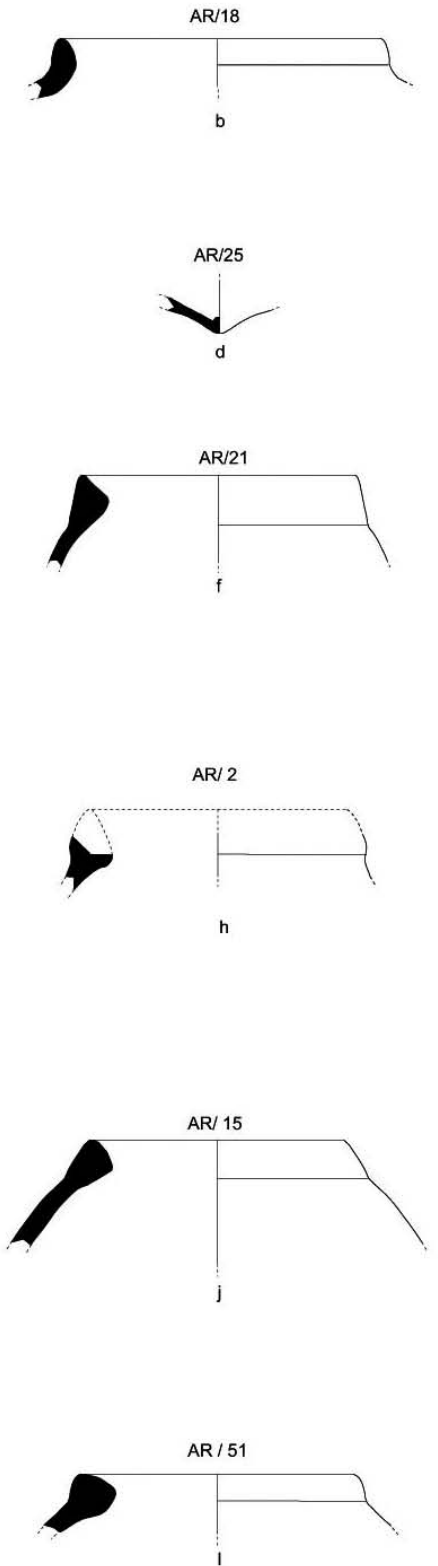

Figura 11. Material anfórico de Altos de Reveque.

tendencia recta (Fig. 12: 1-n). El repertorio se completa con grandes recipientes abiertos, cuencos o fuentes con borde exvasado y cuerpos con paredes de tendencia recta (Fig. 12: h-k) y un fragmento de un borde de jarra (Fig. 13: n). Estas cerámicas pueden datarse en el si- glo vi y en el v a. C., de acuerdo con sus paralelos en la cercana estratigrafía abderitana del Cerro de Montecristo y en la estratigrafía de Baria, así como en algunos casos con producciones coetáneas del horno del Cerro del Villar del siglo v a. C. o las producciones 


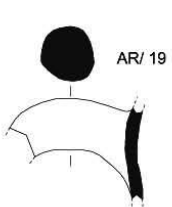

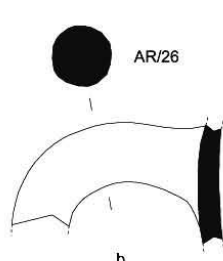
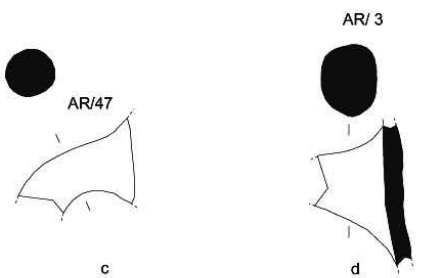

AR/46
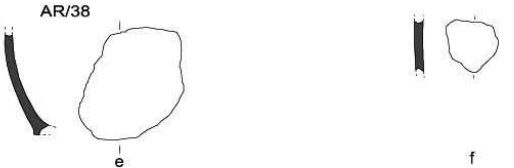

f

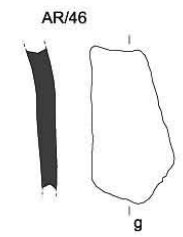

$\mathrm{AR} / 9$
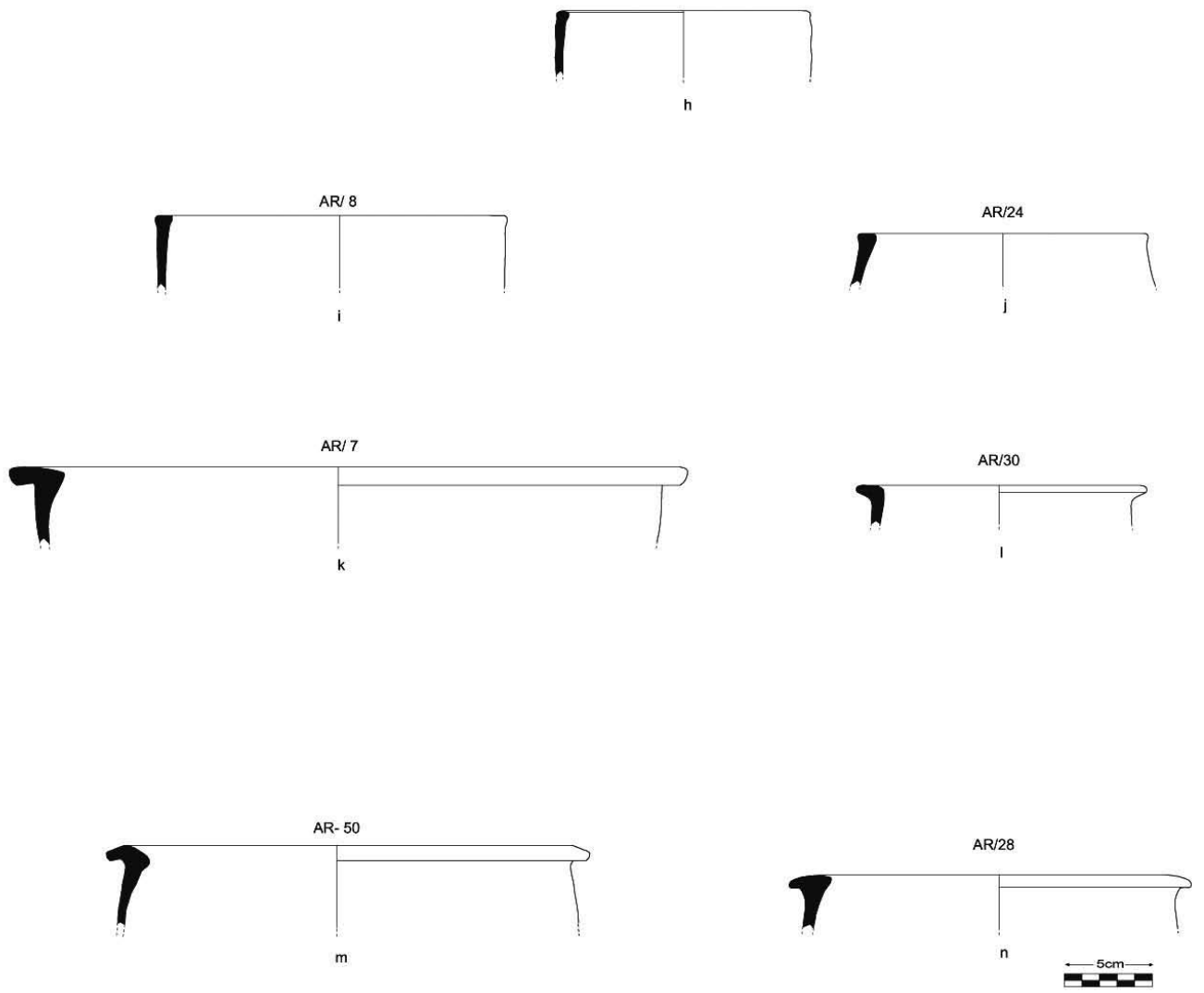

Figura 12. Cerámicas de cocina y comunes.

gaditanas de los hornos de Campo Soto de finales del vi y primera mitad del v a. C. ${ }^{21}$

${ }^{21}$ López Castro; Alcaraz; Santos 2009: (Fig. 3: ch, o); López Castro y otros 2009: (Fig. 5: n, 6: d, 7: c); Aubet y otros 1999, p. 130, fig .87: k; Ramón y otros 2007: pp. 91-92, figs. 161-162.
Otras formas de cerámicas fenicias de mesa han sido documentadas en los Altos de Reveque, tales como un vaso carenado, quizás una copa, de labio curvo que presenta decoración interior con tres bandas de color rojo (Fig. 13: a). Copas similares de los siglos vi y v a. C. se documentan en Abdera, con for- 

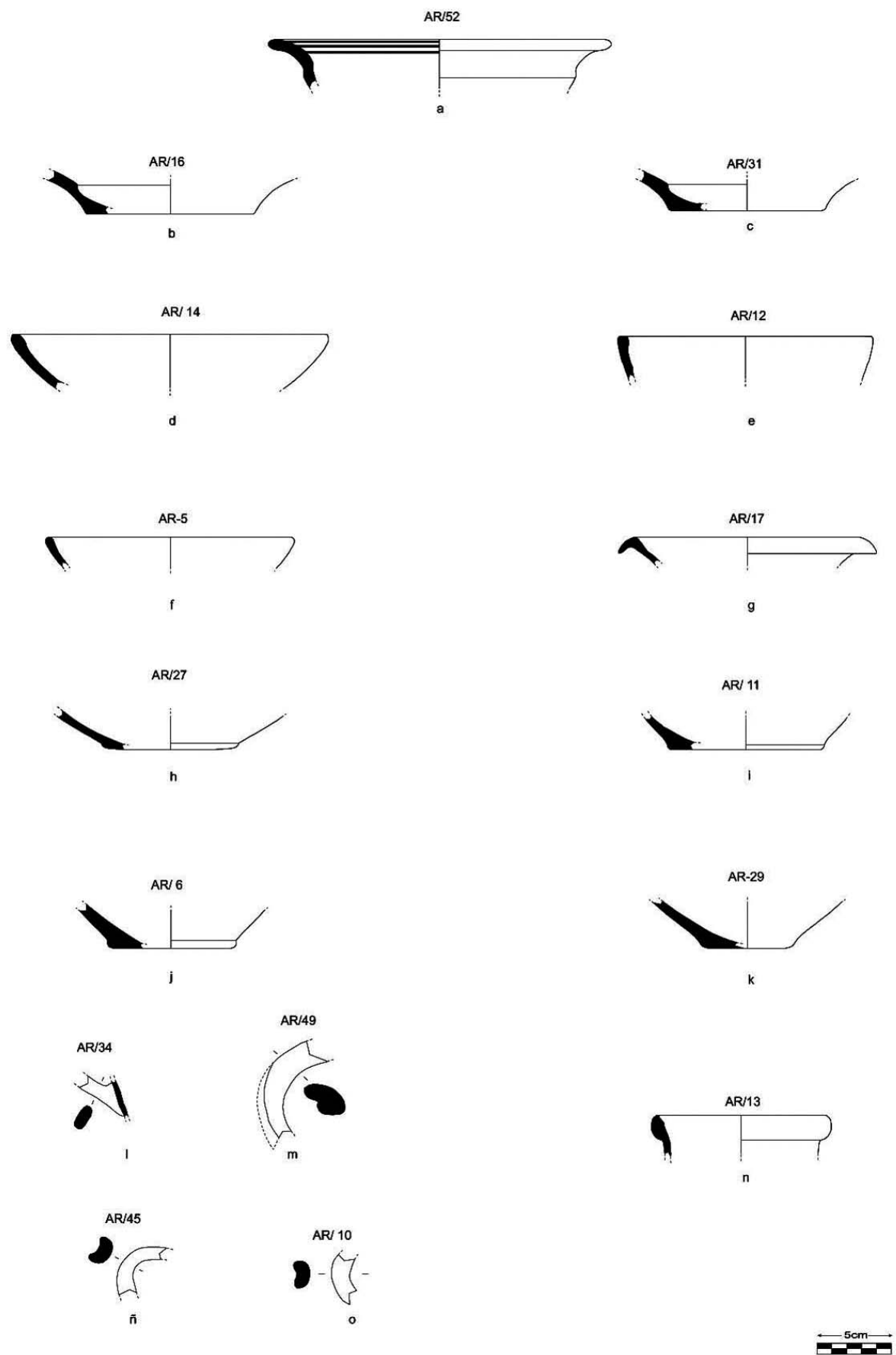

Figura 13. Cerámicas de mesa.

mas precedentes o de similar concepto en los alfares del Cerro del Villar y Campo Soto. ${ }^{22}$ Están pre-

${ }^{22}$ López Castro; Alcaraz; Santos 2009: (Fig. 3: j); Aubet y otros 1999, pp. 165-166, Fig. 104; Ramón y otros 2007, p. 73, Fig. 146. sentes, además, los característicos platos del tipo de borde sencillo o ligeramente vuelto y pocillo central (Fig. 13: b, c) que en ambos casos conservan los característicos engobes claros fenicios de este periodo como tratamiento exterior. Destacan como formas 


\begin{tabular}{|c|c|c|c|c|}
\hline & \multicolumn{2}{|c|}{$\begin{array}{l}\text { MUESTRA } \\
\text { MÉTODO DE MEDIDA }\end{array}$} & $\begin{array}{l}\text { MUESTRA 4A. Mineral inmediaciones del boliche } \\
\text { H1200 (CAPILAR) }\end{array}$ & \multirow[b]{2}{*}{$\%$} \\
\hline REFEREN & NCIA & COMPUESTO & FÓRMULA & \\
\hline \multicolumn{2}{|c|}{$41-1370\left(^{*}\right)$} & Diopside & $\mathrm{Ca}(\mathrm{Mg}, \mathrm{Al})(\mathrm{Si}, \mathrm{Al}) 2 \mathrm{O} 6$ & 18,7 \\
\hline \multicolumn{2}{|c|}{$80-1863(C)$} & Clinopyroxene & (Ca.71Na.20Mg.09)(Mg.74Fe.05Fe.03Ti.01Al.17)(Si1.98Al0.02O6) & 15,3 \\
\hline \multicolumn{2}{|c|}{$01-0136(\mathrm{D})$} & Lepidocrocite & $\mathrm{FeO}(\mathrm{OH}) / \mathrm{Fe} 2 \mathrm{O} 3 \cdot \mathrm{H} 2 \mathrm{O}$ & 9 \\
\hline \multicolumn{2}{|c|}{ 01-0961 (D) } & Silver Sulfate Oxide & $\mathrm{Ag} 2 \mathrm{SO} 4$ & 8,6 \\
\hline \multicolumn{2}{|c|}{$72-1652(C)$} & $\begin{array}{l}\text { Calcite } \\
\text { Cesium Silver Gold }\end{array}$ & $\mathrm{CaCO} 3$ & 8 \\
\hline \multicolumn{2}{|c|}{ 02-0322 (D) } & Chloride & $\mathrm{Cs} 2 \mathrm{AuAgCl} 6$ & 7,7 \\
\hline \multicolumn{2}{|c|}{$01-1151(\mathrm{D})$} & Argentite & $\mathrm{Ag} 2 \mathrm{~S}$ & 7,5 \\
\hline \multicolumn{2}{|c|}{ 03-0812 (D) } & $\begin{array}{l}\text { Hematite } \\
\text { Sodium Calcium }\end{array}$ & $\mathrm{Fe} 2 \mathrm{O} 3$ & 6,9 \\
\hline \multicolumn{2}{|c|}{ 01-1064 (D) } & Silicate & $\mathrm{Na} 4 \mathrm{Ca}(\mathrm{SiO} 3) 3$ & 5,5 \\
\hline \multicolumn{2}{|c|}{ 01-1167 (D) } & $\begin{array}{l}\text { Silver } \\
\text { Silver Phosphate }\end{array}$ & $\mathrm{Ag}$ & 5,6 \\
\hline \multicolumn{2}{|c|}{ 01-1058 (D) } & Oxide & $\mathrm{Ag} 3 \mathrm{PO} 4$ & 3,6 \\
\hline \multicolumn{2}{|c|}{$76-0940$ (C) } & Cristobalite low & $\mathrm{SiO} 2$ & 3,6 \\
\hline
\end{tabular}

\begin{tabular}{|c|c|c|c|c|}
\hline \multicolumn{2}{|c|}{$\begin{array}{l}\text { MUESTRA } \\
\text { MÉTODO DE MEDIDA }\end{array}$} & \multicolumn{3}{|c|}{$\begin{array}{l}\text { MUESTRA } 11 \text { B. Escoria próxima al boliche } \\
\text { H1200 (CAPILAR) }\end{array}$} \\
\hline REFERENCIA & \multicolumn{2}{|c|}{ COMPUESTO } & FÓRMULA & \\
\hline 01-0739 (D) & \multicolumn{2}{|c|}{ Albite } & NaAISi3O8 & 6,4 \\
\hline $75-0856$ (C) & \multicolumn{2}{|c|}{ Pyrophyllite } & $\mathrm{Al} 2 \mathrm{Si} 4 \mathrm{O} 10(\mathrm{OH}) 2$ & 3 \\
\hline $76-0940$ (C) & \multicolumn{2}{|c|}{ Cristobalite low } & $\mathrm{SiO} 2$ & 1,9 \\
\hline 01-1167 (D) & \multicolumn{2}{|c|}{ Silver } & $\mathrm{Ag}$ & 5,1 \\
\hline 83-0539 (C) & \multicolumn{2}{|l|}{ Quartz } & $\mathrm{SiO} 2$ & 3,9 \\
\hline 75-0948 (C) & \multicolumn{2}{|c|}{ Muscovite } & KAI3Si3O10(OH)2 & 1,6 \\
\hline $41-1486\left(^{*}\right)$ & \multicolumn{2}{|c|}{ Anorthite, ordered } & $\begin{array}{l}\mathrm{CaAl} 2 \mathrm{Si} 2 \mathrm{O} 8 \\
(\mathrm{NH} 4) 2 \mathrm{Cu}(\mathrm{SO} 4) 2 \cdot 6 \mathrm{H} 2\end{array}$ & 32,1 \\
\hline 01-0410 (D) & \multicolumn{2}{|c|}{ Ammonium Copper Sulfate Hydrate } & $\mathrm{O}$ & 2,3 \\
\hline 01-0710 (D) & \multicolumn{2}{|c|}{ Potassium Sulfur Oxide } & $\mathrm{K} 2 \mathrm{~S} 2 \mathrm{O} 8$ & 21,8 \\
\hline 01-1003 (D) & \multicolumn{2}{|c|}{ Potassium Iron Oxide } & $\mathrm{K} 2 \mathrm{Fe} 2 \mathrm{O} 4$ & 21,8 \\
\hline
\end{tabular}

Figura 14. Análisis de muestras de minerales del boliche moderno.

más abundantes los cuencos aproximadamente hemisféricos, de borde simple o a veces algo engrosado al interior y pies ligeramente indicados (Fig. 13: d-f, hk). Ambos tipos se encuentran bien documentadas en las estratigrafías de Abdera y Baria en los siglos vi y $\mathrm{v}$ a. C., proyectándose también en periodos posteriores, así como en estratos del último tercio del siglo vi a. C. en Malaka. ${ }^{23}$

Un hecho a resaltar es la ausencia en superficie de cerámicas iberas, lisas o decoradas, que suelen documentarse abundantemente en los asentamientos iberos tipo oppidum de carácter fortificado, como sucede en el vecino oppidum del Cerrón de Dalías. ${ }^{24}$

Anteriormente hicimos referencia a la recogida de muestras de mineral en el yacimiento y sus inmedia-

\footnotetext{
${ }^{23}$ López Castro 2007: p. 31, Fig. 6; López Castro; Alcaraz; Santos 2009: (Fig. 3: f, i); López Castro y otros 2009 (Figs. 5: ̃-q, 6: e, i-k, rr-t, 7: f); Arancibia; Escalante 2006: p. 66 , Fig. 24.

${ }^{24}$ Cara 1999: 120.
}

ciones. Las analíticas por Difracción de Rayos $\mathrm{X}^{25}$ efectuadas a muestras de mineral procedentes de asentamiento de Altos de Reveque y sus inmediaciones confirman la existencia de minerales con contenido en plata en la zona y su explotación en la Antigüedad y en época moderna. La muestra de mineral $n^{\circ} 4 \mathrm{~A}$ (Fig. 14) tomada en las escombreras del boliche del siglo XIX, actualmente destruido y situado en la ladera sur del yacimiento arqueológico aporta en su composición un contenido elevado de plata $(5,6 \%)$ y compuestos de plata (sulfuro de plata, óxido de plata, argentita, clorida), así como una alta proporción de mineral de hierro en forma de hematites (muestra 4B: $64,2 \%$ ).

Por su parte, una muestra de escoria de fundición de mineral tomada también de dichas escombreras, la

${ }^{25}$ Las muestras fueron analizadas en el Servicio de Difracción y Fluorescencia de Rayos X de la Universidad de Almería por la Dra. Sonia Mañas Carpio. 


\begin{tabular}{|c|c|c|c|c|}
\hline \multicolumn{2}{|c|}{$\begin{array}{l}\text { MUESTRA } \\
\text { MÉTODO DE MEDIDA }\end{array}$} & \multicolumn{3}{|c|}{$\begin{array}{l}\text { MUESTRA } 8 \text { B. Mineral área Sur, edificios } \\
\text { H1200 }\end{array}$} \\
\hline REFERENCIA & \multicolumn{2}{|c|}{ COMPUESTO } & FÓRMULA & $\%$ \\
\hline $41-1370\left(^{*}\right)$ & \multicolumn{2}{|c|}{ Diopside } & $\mathrm{Ca}(\mathrm{Mg}, \mathrm{Al})(\mathrm{Si}, \mathrm{Al}) 2 \mathrm{O} 6$ & 36 \\
\hline 01-0842 (D) & \multicolumn{2}{|c|}{ Chalcopyrite } & CuFeS2 & 12,8 \\
\hline 01-0739 (D) & \multicolumn{2}{|c|}{ Albite } & $\mathrm{NaAISi} 3 \mathrm{O} 8$ & 9,6 \\
\hline $75-0856(C)$ & \multicolumn{2}{|c|}{ Pyrophyllite } & $\mathrm{Al} 2 \mathrm{Si} 4 \mathrm{O} 10(\mathrm{OH}) 2$ & 8,5 \\
\hline 03-0812 (D) & \multicolumn{2}{|c|}{ Hematite } & $\mathrm{Fe} 2 \mathrm{O} 3$ & 7,3 \\
\hline $72-1652(C)$ & \multicolumn{2}{|c|}{ Calcite } & $\mathrm{CaCO} 3$ & 6,2 \\
\hline $76-0940(\mathrm{C})$ & \multicolumn{2}{|c|}{ Cristobalite low } & $\mathrm{SiO} 2$ & 6,1 \\
\hline 01-0679 (D) & \multicolumn{2}{|c|}{ Zircon } & $\mathrm{ZrSiO} 4$ & 5,4 \\
\hline 01-1058 (D) & \multicolumn{2}{|c|}{ Silver Phosphate Oxide } & $\mathrm{Ag} 3 \mathrm{PO} 4$ & 4,2 \\
\hline 01-1167 (D) & \multicolumn{2}{|c|}{ Silver } & $\mathrm{Ag}$ & 4 \\
\hline
\end{tabular}

\begin{tabular}{|l|l|}
\hline $\begin{array}{l}\text { MUESTRA } \\
\text { MÉTODO DE MEDIDA }\end{array}$ & MUESTRA 8 C. Mineral área Sur, edificios \\
H1200 (CAPILAR)
\end{tabular}

\begin{tabular}{|c|c|c|c|}
\hline REFERENCIA & COMPUESTO & FÓRMULA & $\%$ \\
\hline $41-1370\left(^{*}\right)$ & Diopside & $\mathrm{Ca}(\mathrm{Mg}, \mathrm{Al})(\mathrm{Si}, \mathrm{Al}) 2 \mathrm{O} 6$ & 26,2 \\
\hline 01-0739 (D) & Albite & $\mathrm{NaAISi} 3 \mathrm{O} 8$ & 9,7 \\
\hline $75-0856(\mathrm{C})$ & Pyrophyllite & $\mathrm{Al} 2 \mathrm{Si} 4 \mathrm{O} 10(\mathrm{OH}) 2$ & 5,3 \\
\hline 03-0812 (D) & Hematite & $\mathrm{Fe} 2 \mathrm{O} 3$ & 5,5 \\
\hline $76-0940(\mathrm{C})$ & Cristobalite low & $\mathrm{SiO} 2$ & 2,7 \\
\hline 01-1167 (D) & Silver & $\mathrm{Ag}$ & 3,1 \\
\hline $83-1703(C)$ & Margarite $2 \mathrm{M} 1$ & $\mathrm{CaAl} 2(\mathrm{Si} 2 \mathrm{Al} 2 \mathrm{O} 10)(\mathrm{OH}) 2$ & 13,9 \\
\hline $81-0994(C)$ & Potassium Iron Oxide & $\mathrm{K} 6(\mathrm{Fe} 2 \mathrm{O} 5)$ & 2,7 \\
\hline $80-2186(\mathrm{C})$ & $\begin{array}{l}\text { Iron Oxide } \\
\text { Sodium Hydrogen Aluminum Silicate }\end{array}$ & $\mathrm{Fe} 21.34 \mathrm{O} 32$ & 0,5 \\
\hline $79-1478(C)$ & Zeolite NaLZ210, syn & $\mathrm{Na} 31.2 \mathrm{H} 1.8(\mathrm{Al} 32.5 \mathrm{Si} 159.5 \mathrm{O} 384)$ & 2,6 \\
\hline $10-0393\left(^{*}\right)$ & Albite, disordered & $\mathrm{Na}(\mathrm{Si} 3 \mathrm{Al}) \mathrm{O} 8$ & 5,7 \\
\hline 01-0842 (D) & Chalcopyrite & CuFes2 & 22,1 \\
\hline
\end{tabular}

Figura 15. Análisis de muestras de minerales del interior del recinto.

muestra $n^{\circ} 11 \mathrm{~B}$ (Fig. 14), contiene un contenido en plata del $5,1 \%$. Estas muestras nos están informando de la existencia en las cercanías del boliche de minerales de plata y hierro que fueron explotados y beneficiados en época moderna, y que probablemente fueron ya explotados en la Antigüedad. Los resultados del análisis de la muestra ${ }^{\circ} 8 \mathrm{~B}$ (Fig. 15), recogida en superficie en el interior del recinto fortificado, concretamente en el área de edificios próxima a la muralla sur es extraordinariamente reveladora de las actividades vinculadas a la fortificación de Altos de Reveque. La muestra presenta calcopiritas $(12,8 \%)$ con cobre e hierro, así como plata pura (4\%) y óxido de plata $(4,2 \%)$. Un segundo análisis de otra faceta de la muestra, no $8 \mathrm{C}$ (Fig. 15), contiene además de un $22 \%$ de calcopiritas, un $3,1 \%$ de plata pura.

\section{LA TIPOLOGÍA DE LA MURALLA}

Las murallas de doble paramento con compartimentos interiores en la arquitectura militar fenicia y cartaginesa suelen ser denominadas murallas de casamatas o casernas, o murallas de cajones, dependiendo de la funcionalidad de dichos compartimentos. ${ }^{26}$ Mientras que las casamatas solían estar vacías y se empleaban como almacenes o estancias de habitación, los cajones estaban permanentemente rellenos de escombros, tierra prensada o arcilla a fin de dotar de solidez a la base de la muralla y resistir los embates de los arietes en caso de asedio.

En la muralla de los Altos de Reveque los compartimentos interiores se disponen en las murallas norte, oeste y sur y su superficie varía en función de la separación de los muros exterior e interior de aquellas. Aunque en superficie no se han podido documentar todos los tirantes, parece claro que las tres murallas estuvieron originalmente compartimentadas en su completa extensión. Con la información recabada en superficie es difícil saber si los compartimentos interiores estuvieron rellenos de arcilla, pudiendo hablar entonces de una muralla de cajones; si por el contrario estaban vacíos y se destinaron al almacenamiento y la vivienda o si se alternaron ambas 
posibilidades en los distintos paños. Sólo una excavación arqueológica podría determinar el uso de los compartimentos interiores.

$\mathrm{Si}$ admitimos que se trata de una muralla de doble paramento, nos alejamos de los sistemas de amurallamiento empleados por los iberos, que al contrario de lo que sucede entre los fenicios, construyeron casi exclusivamente las murallas con muros simples ${ }^{27}$ en muchos casos con las viviendas adosadas a la cara interior de la muralla. Significativamente, sólo se conoce un caso de muralla de casamatas en un asentamiento ibero, es el caso de El Turó del Montgròs (El Brull, Barcelona) que sin embargo se data a finales del siglo III a. C. o principios del II a. C. y su tipología se atribuye a la influencia helenística a través de la ciudad griega de Emporion. ${ }^{28}$ Tampoco los sistemas defensivos iberos más sofisticados, como el documentado en el Puig de la Nau o la Bastida de les Alcusses, por mencionar algunos ejemplos, ${ }^{29}$ guardan semejanza con las murallas de tipo oriental de doble paramento y compartimentos interiores.

Aunque contamos con asentamientos fenicios que presentan murallas macizas con torres, como la segunda muralla del Alarcón en Toscanos, de finales del siglo VII a. C. o uno de los tramos de la muralla de La Fonteta, en Guardamar de Segura, de finales del siglo vIII a. C. ${ }^{30}$ la muralla del tipo de doble paramento y compartimentos interiores, en sus variedades de cajones y casamatas, fue la tipología más utilizada por los fenicios occidentales.

Este tipo de obras de fortificación tiene su origen en Fenicia y Siria-Palestina, donde se empleó por primera vez en los asentamientos de Tell-Kabri, Gezer, Azor, Meggido y Samaria durante los siglos $\mathrm{x} y \mathrm{IX}$ a. C. Su origen se ha relacionado con la invención por parte de los asirios del ariete como máquina de asedio. ${ }^{31}$ Los colonizadores fenicios transmitirían esta técnica constructiva al Extremo Occidente desde fechas muy tempranas. Este es el caso de la más antigua de las murallas fenicias conocidas en la Península Ibérica, la de Castillo de Doña Blanca (Puerto de Santa María, Cádiz) fechada a mediados del si-

\footnotetext{
${ }^{26}$ Montanero 2008: 96, 98 ss.; Blánquez 2008: 159, 163

${ }^{27}$ Moret 1996: 83-84; Bonet 2006: 18, 24-27

${ }^{28}$ Moret 1996: 213-214, 385-386.

${ }^{29}$ Dies Cusí 2006; Sala 2006.

30 Schubart 2000: 264; González Prats 2007: 77 ss.; Prados; Blánquez 2007: 60 ss.

${ }^{31}$ Sobre estos asentamientos vid. E. M. Meyers (ed.): The Oxford Encyclopedia of Archaeology in the Near East, Oxford 1997, vol. 3, p. 261, 1-5, 460-469; vol. 5, pp. 19-23; vol. 2, pp. 396-400; vol. 4, pp. 463-467; Wright 1985: $173-$ 174, Fig. 86; Pastor 2008: 11 ss.; Montanero 2008: 98-99.
}

glo viII a. C., o la del Cabezo del Estaño en Guardamar de Segura, también construida en el periodo colonial a finales de ese siglo o comienzos del viI a. C. ${ }^{32}$

Pero fue con el proceso de formación de ciudades desde algunos asentamientos coloniales, ${ }^{33}$ a partir de finales del siglo viI a. C., cuando se generalizaron las murallas en las ciudades fenicias occidentales: de hecho, la mayoría de las que conocemos son de compartimentos interiores: es el caso de la muralla de Malaka de comienzos del siglo vi a. C., el caso de la muralla de Abdera, recientemente descubierta por nosotros, o la muralla del siglo v a. C. de Castillo de Doña Blanca, que guarda un notable paralelismo en sus proporciones con la muralla oeste de Altos de Reveque y unas medidas similares en el doble paramento: dos codo el exterior y uno el interior. ${ }^{34}$ No obstante, el precedente tipológico más cercano de la muralla de Altos de Reveque es la muralla de cajones de Abdera documentada en el transcurso de las excavaciones arqueológicas de 2006 en el Cerro de Montecristo de Adra fechada hacia finales del siglo vII a. C. o comienzos del vi y que guarda a su vez medidas idénticas a las de Reveque: dos codos en el paramento exterior, uno en el interior y en los tirantes. ${ }^{35}$

Con posterioridad al periodo mencionado se documentan murallas de compartimentos como la de Carteia del siglo IV a. C. y ya bajo la conquista cartaginesa, a finales del siglo III a. C., se construyeron las nuevas murallas de esta tipología de Castillo de Doña Blanca, Carteia y Carthago Nova a las que se ha atribuido una influencia helenística en su concepción arquitectónica. ${ }^{36}$

\section{LA FUNCIONALIDAD DE ALTOS DE REVEQUE: UNA PROPUESTA DE INTERPRETACIÓN}

Durante décadas el paradigma comercial —la interpretación de la historia de los fenicios que explicaba todas sus manifestaciones exclusivamente por la actividad comercial— había confinado la presen-

\footnotetext{
32 Ruiz Mata; Pérez 1995: 99 ss.; Ruiz Mata 2001: 264; García Menárguez 1994: 226 ss.; González Prats; García Menárguez 2000: 1528 ss.

${ }^{33}$ López Castro 2003.

${ }^{34}$ Arancibia; Escalante 2006: 62 ss.; López Castro y otros e.p.; Ruiz Mata 2001: 266.

${ }^{35}$ Una valoración en D. Montanero 2008: 111; López Castro y otros e.p., López Castro 2009: 463-465.

${ }^{36}$ Ruiz Mata 2001: 267-268; Prados; Blánquez 2007: 64 ss.; Marín 1997-98; Montanero 2008: 116 ss.; Bendala; Blanquez 2005; Roldán y otros 2006: 301 ss.
} 
cia fenicia en el Occidente mediterráneo a la costa, en el sentido más estricto, para realizar la única misión que era posible concebir para ellos: comerciar. Diversos proyectos de campo de los últimos decenios mostraron cómo, desde los asentamientos coloniales, se explotaban los recursos de un territorio reducido, con poca proyección al interior, y cómo las actividades productivas, tanto primarias como secundarias, eran tan variadas como en cualquier otra sociedad antigua.

La estructuración de los fenicios occidentales en ciudades-estado a partir de finales del siglo vir a.C. implicaría el control de territorios ciudadanos y la existencia de un poblamiento rural que, no por poco investigado es menos evidente. En un reciente trabajo, con ocasión de revisar y reunir los datos sobre dicho poblamiento, nos planteábamos la hipótesis de que tales territorios ciudadanos estuviesen protegidos y fortificados y la necesidad de abrir ese debate, pues parecía a veces que las fortificaciones litorales sólo podían ser atribuidas a los iberos. ${ }^{37}$ No imaginábamos entonces que el hallazgo del asentamiento de Altos de Reveque podría contribuir a confirmar la hipótesis esbozada, abriendo perspectivas completamente inéditas en nuestra concepción de la presencia fenicia en el Extremo Occidente en el periodo comprendido entre los siglos VI y III a. C., en caso de que ulteriores investigaciones arqueológicas corroborasen los datos obtenidos en superficie.

Desde este punto de vista, el asentamiento de Altos de Reveque parece ser una fundación ex novo promovida desde la ciudad fenicia de Abdera $^{38}$ para el control de la explotación de recursos y para el control estratégico del litoral. Los recursos explotados podrían ser fundamentalmente mineros, agrícolas y forestales. Nuestras excavaciones arqueológicas en Abdera han aportado datos sobre el beneficio del plomo, el hierro y la plata a través de los análisis en curso de escorias de fundición de mineral, así como el aprovisionamiento de madera de diversas especies arbóreas propias de cotas elevadas. Altos de Reveque permitiría también la explotación agrícola en el Campo de Dalías: podemos relacionar su fundación, al menos como hipótesis, con el poblamiento de carácter fenicio-púnico en el Poniente almeriense. Es posible que la fundación también ex novo de la fase constructiva del siglo v a. C. de Ciavieja, en El Ejido ${ }^{39}$ pudiera relacionarse con esta hipótesis por

\footnotetext{
${ }^{37}$ López Castro 2008: 159-160.

${ }^{38}$ Suárez y otros 1989; López Castro 2006.

${ }^{39}$ Suárez y otros 1985; 1986.
}

el carácter fenicio-púnico de los materiales. De hecho Ciavieja ha suscitado diversas interpretaciones sobre su origen, aunque cobra fuerza la que relaciona este asentamiento con una fundación promovida desde la vecina Abdera para la explotación de los recursos agrícolas. ${ }^{40}$

Excluida la funcionalidad urbana, y a juzgar por su emplazamiento, es posible atribuir al recinto amurallado de Altos de Reveque una funcionalidad militar y de carácter estratégico, destinada a la defensa de los recursos naturales de la zona, al control territorial y al control del tráfico marítimo costero mediante el establecimiento de un punto fortificado.

La apropiación y el mantenimiento de recursos naturales por parte de una ciudad fenicia como fue Abdera requería una proyección territorial que se fundamentó en la construcción de una potente fortificación del tipo de muralla de doble paramento y compartimentos interiores, el tipo más extendido en las fortificaciones fenicias de la Península Ibérica; un modelo que está documentado asimismo en Abdera, donde la muralla de la ciudad de finales del siglo VII a. C. o principios del vi se adscribe a esta tipología en la variedad de muralla de cajones.

De acuerdo con la cronología de los hallazgos cerámicos superficiales, el asentamiento de Altos de Reveque podría fecharse, como muy antiguo, a mediados del siglo vi a. C. y su vida se extendería a lo largo del siglo v, para abandonarse a finales del mismo o, como muy tarde, en los primeros decenios del siglo IV a. C. Obviamente, sólo datos de excavación estratigráfica podrían confirmar o matizar estas cronologías.

El coste de la construcción de las fortificaciones y el mantenimiento de una guarnición permanente, durante un periodo de ocupación que podemos cifrar en algo más de 150 años aproximadamente, pueden justificarse por la explotación de minerales de plata, plomo e hierro en la Sierra de Gádor, de los cuales hay traza de su presencia en el interior del asentamiento y en sus inmediaciones.

La existencia de un importante oppidum ibero más antiguo en las cercanías, el Cerrón de Dalías posiblemente contemporáneo a los Altos de Reveque e identificable quizá con el emplazamiento de la Murgi mencionada en las fuentes literarias, resta sentido a la construcción de una compleja y costosa fortificación a instancias de los grupos dirigentes iberos del Cerrón de Dalías para cubrir y proteger un mismo territorio con un asentamiento tan cercano, duplicando

${ }^{40}$ Carrilero; López Castro 1994: 264 ss.; Carrilero Millán; López Medina 1998: 34. 
la función del oppidum. Documentos iberos como el plomo de Gádor, una inscripción hallada en 1862 que se ha interpretado como un documento de contabilidad minera, ${ }^{41}$ puede relacionarse con la explotación por los iberos de los recursos mineros de la Sierra de Gádor. Del mismo modo, el hallazgo en las costas de Murcia de un conjunto de plomos monetiformes con leyenda ka.i.tur atribuidos a una entidad ibera denominada gaidur o Gador ha sido también puesto en relación con dicha explotación. ${ }^{42}$

Aunque estos documentos se datan en los siglos II y i a. C., lejos por tanto del periodo de ocupación de Altos de Reveque, nos indican que el control de los recursos mineros de la zona era ejercido por los iberos, posiblemente desde tiempo atrás. La existencia de una fortaleza fenicia frente a un oppidum ibero no puede sino inducirnos a pensar en la existencia de un acceso diferenciado a los recursos de fenicios e iberos, ya fuera como resultado de un conflicto, ya mediante un pacto que quedaría garantizado por la construcción de una fortificación como Altos de Reveque. La solución escapa a nuestras posibilidades de interpretación, sin estudios espaciales más profundos que permitieran comprobar la existencia paralela y coetánea de sistemas de control territorial fenicios e iberos en la zona.

Para concluir, a la vista de los datos expuestos podemos proponer que, sin perjuicio de que ulteriores investigaciones en profundidad pudieran aportar datos más concluyentes, el asentamiento fortificado de Altos de Reveque se fundó a mediados o en la segunda mitad del siglo vi a. C. posiblemente para garantizar el acceso de la ciudad fenicia de Abdera a los recursos mineros y forestales de la Sierra de Gádor, en particular la plata y tal vez a los recursos agrícolas del Campo de Dalías. El análisis de las distintas evidencias materiales aconseja descartar que pudiera tratarse de un oppidum ibero. El asentamiento reunía también una notable capacidad de proyección estratégica y de control visual del litoral en beneficio de la ciudad fenicia de Abdera. Por sus características el asentamiento fortificado de Altos de Reveque es único en la Península Ibérica, contiene un alto potencial para la investigación y nos informa de aspectos hasta ahora inéditos de la historia de la presencia fenicia en la Península Ibérica, que nos obligan a replantear y modificar el papel histórico de la misma.

41 Untermann 1990: H 1; Almagro; Álvarez Sanchís 1998: 57.

${ }^{42}$ García-Bellido 2001: 338-339.

\section{BIBLIOGRAFÍA}

Almagro Gorbea, M.; Álvarez-Sanchís, J. (1998): Archivo del Gabinete de Antigüedades. Catálogo $e$ índices. Madrid, Real Academia de la Historia.

Álvarez de Linera, A. (1851): «Sierra de Gádor», Revista Minera II, 417-424.

Arancibia Román, A.; Escalante Aguilar, M. M. (2006): «Génesis y consolidación de la ciudad de Malaka». Memoria arqueológica del Museo Picasso. Málaga. Desde los orígenes hasta el siglo v d. C.. Málaga, Museo Picasso, 41-78.

Artero García, J. M. (1986): «Síntesis geológicominera de la provincia de Almeria». Boletín del Instituto de Estudios Almerienses 6, 57-59.

Aubet, $\mathrm{M}^{\mathrm{a}}$ E.; Carmona, P.; Curiá, E.; Delgado, A.; Fernández A.; Párraga, A. (1999): Cerro del Villar I. El asentamiento fenicio en la desembocadura del río Guadalhorce y su interacción con el hinterland. Sevilla, Consejería de Cultura.

Barresi, P. (2007): Metrología púnica. Milano, Athenaion.

Bendala Galán, M.; Blánquez Pérez, J. (2005): «arquitectura militar púnico-helenística en Hispania». Cuadernos de Prehistoria y Arqueología de la Universidad Autónoma de Madrid 28-29, $145-$ 159.

Blánquez Pérez, J. (2008): «Arquitectura defensiva del suroeste de la Península Ibérica». B. Costa; J. H. Fernández (eds.): Arquitectura defensiva fenicio-púnica, XXII Jornadas de Arqueología Fenicio-Púnica (Eivissa 2007). Ibiza, Consellería d'Educació i Cultura, 145- 183. Treballs del Museu Arqueologic d'Eivissa i Formentera 61.

Bonet Rosado, H. (2006): «Tres modelos de arquitectura defensiva y protección del territorio. Edeta, Kelin y la Bastida de les Alcuses». A. Oliver Foix (coord.): Arquitectura defensiva. La protección de la población y del territorio en época ibérica, Castellón, Sociedad Castellonense de Cultura, 13-45.

Cara Barrionuevo, L. (1999): «El Cerrón de Dalías y la antigua Ulisseia». Farua 2, 119-128.

Cara Barrionuevo, L.; Rodríguez López, J.M (1986): «Notas para el estudio de la minería almeriense anterior al siglo XIX». Boletín del Instituto de Estudios Almerienses. Letras 6, 11-24.

Cara Barrionuevo, L. (2002): La minería de Sierra de Gádor, nuestro legado. Berja, Concejalía de Cultura.

Cara Barrionuevo, L.; Vázquez Guzmán, J. P. (eds.) (2008): La minería preindustrial en Almería y el sudeste. Almería, Instituto de Estudios Almerienses, Fundación Cajamar. 
Carrilero Millán, M.; López Castro, J.L. (1994): «Ciavieja: un asentamiento de época púnica en el Poniente almeriense». A. González Blanco; J.L. Cunchillos; M. Molina (coords.): El mundo púnico. Historia, sociedad y cultura, Coloquios de Cartagena, I, Cartagena 1990. Murcia, Editora Regional Murciana, 251-268.

Carrilero Millán, M.; López Medina, Ma J. (1998): «Murgi. El Ejido durante la Antigüedad». A. Suárez; M. Carrilero; M.J. López; J. J. Egea: Patrimonio histórico de El Ejido. El Ejido, Ayuntamiento de El Ejido, 29-54.

Contreras Barón, D.; García Sánchez, J. (2008): Informe sobre cavidades en Altos del Reveque. Informe policopiado, Almería.

Corchete V.; Chourak M.; Khattach D. (2005): «The High-resolution gravimetric geoid of Iberia: IGG 2005». Geophysical Journal International 162, 676-684.

Díes Cusí, E. (2006): «El sistema defensivo del Puig de la Nau (Benicarló). Análisis y propuesta de restitución». A. Oliver Foix (coord.): Arquitectura defensiva. La protección de la población y del territorio en época ibérica. Castellón, Sociedad Castellonense de Cultura, 47-61.

Domergue, C. (1987): Catalogue des mines et des fonderies de la Peninsule Iberique. Madrid, Casa Velázquez, t. I.

Domergue, C. (1990): Les mines de la Péninsule Ibérique dans l'antiquité romaine. Rome, Ècole Française de Rome.

García-Bellido, $M^{\mathrm{a}}$ P. (2001): «Plomos monetiformes con el topónimo ibérico de Gador». Paleohispanica 1, 335-340.

García Menárguez, A. (1994): «El Cabezo Pequeño del Estaño, Guardamar del Segura: un poblado protohistórico en el tramo final del río Segura». A. González Blanco; J.L. Cunchillos; M. Molina (coords.): El mundo púnico. Historia, sociedad y cultura, Coloquios de Cartagena, I, Cartagena 1990. Murcia, Editora Regional Murciana, 269-280.

González Prats, A. (2007): «Rasgos arquitectónicos y urbanísticos de La Fonteta». J.L. López Castro (ed.): Las ciudades fenicio-púnicas en el Mediterráneo Occidental. Almería, Editorial Universidad de Almería- Centro de Estudios Fenicios y Púnicos, 69-82.

González Prats, A.; García Menarguez, A. (2000): «El conjunto fenicio de la desembocadura del río Segura, (Guardamar del Segura, Alicante)». M. Barthelemy; $\mathrm{M}^{\mathrm{a}}$ E. Aubet Semmler (coords.): Actas del IV Congreso Internacional de Estudios Fenicios y Púnicos, Cádiz 1995, vol. 4, 1527-1537.
López Castro, J.L. (2003): «La formación de las ciudades fenicias occidentales», Byrsa. Rivista di archeologia, arte, e cultura punica 2, 69-120.

López Castro, J.L. (2005): Informe final del proyecto: Producción y comercio fenicio-púnico en el litoral almeriense durante el I milenio a.C. Informe policopiado, Almería, Instituto de Estudios Almerienses.

López Castro, J.L. (2006): «Abdera fenicia. Nueve siglos de historia». J. Sánchez Real (coord.): Historia de Adra. Almería, 29-42. Farua extra 1.

López Castro, J.L. (2007): «La ciudad fenicia de Baria. Investigaciones 1987-2003». Actas de las Jornadas sobre la Zona Arqueológica de Villaricos, Almería 2005. Sevilla, Consejería de Cultura, 19-39.

López Castro, J.L. (2008): «El poblamiento rural fenicio en el sur de la Península Ibérica entre los siglos VI a III a.C.». Gerión 26, 1 (2008), 145172.

López Castro, J.L. (2009): «Las ciudades de Abdera y Baria en el sureste de la Península Ibérica. Topografía y urbanismo». S. Helas; D. Marzoli (eds.): Phönizisches und punisches Stätdewesen. Mainz, P. von Zabern, 461-472.

López Castro, J.L.; Alcaraz, F.; Santos, A. (2009): «Informe preliminar de la intervención arqueológica en el Cerro de Montecristo (Adra, Almería)». Anuario Arqueológico de Andalucía 2004, vol I, Actividades puntuales y sistemáticas, 1-18.

López Castro, J.L.; Alemán Ochotorena, B.; Martínez Hahnmüller, V.; Moya Cobos, L.; Pardo Barrionuevo, C.; Santos Payán, A. (e. p.): «Excavaciones arqueológicas en Abdera. La campaña de 2006 en el Cerro de Montecristo de Adra». Аnиario Arqueológico de Andalucía 2006.

López Castro, J.L.; Alcaraz Hernández, F.; Ortiz Soler, D.; Santos Payán, D.; Martínez Hahnmüller, V. (2009): «Informe sobre la excavación de urgencia efectuada en 2003 en el solar de la calle 'La Central' de Villaricos (Cuevas del Almanzora)». Anuario Arqueológico de Andalucía 2004 vol. III, Actividades de urgencia, 4961.

Madoz, P. (1845-1850): Diccionario geográfico-estadístico-histórico de España y sus posesiones de ultramar, Tomo VIII. Madrid (ed. facsímil Almendralejo, Biblioteca Santa Ana, 1983).

Maestre, A. (1844): «Ojeada geognóstica y minera sobre el litoral del Mediterráneo desde el Cabo de Palos hasta el Estrecho de Gibraltar». Anales de Minas 4, 145-177.

Manzano-Agugliaro, F.; Montero Rodríguez, M.A 
(2004): «Desarrollo de una metodología de control de la cartografía catastral urbana mediante GPS». CT-Catastro 50, 103-120.

Marín Baño, C. (1997-98): «Un modelo estratigráfico de la Cartagena púnica: la muralla de Qart-Hadast». Anales de Prehistoria y Arqueología 13-14, 121-140.

Meyers, E. M. (ed.), (1997): The Oxford Encyclopedia of Archaeology in the Near East. Oxford, Oxford University Press.

Montanero, D. (2008): «Los sistemas defensivos de origen fenicio-púnico del sureste peninsular (siglos VIII-III a.C.): nuevas interpretaciones». B. Costa; J. H. Fernández (eds.): Arquitectura defensiva fenicio-púnica, XXII Jornadas de Arqueología Fenicio-Púnica (Eivissa 2007). Ibiza, Consellería d'Educació i Cultura, 91-144. Treballs del Museu Arqueologic d'Eivissa i Formentera 61.

Moret, P. (1996): Les fortifications ibériques. De la fin de l'Âge du Bronze à la conquête romaine. Madrid, Casa de Velázquez.

Pastor Borgoñón, H. (2008): «Arquitectura defensiva en Fenicia oriental y en el norte de Israel/Palestina». B. Costa; J. H. Fernández (eds.): Arquitectura defensiva fenicio-púnica, XXII Jornadas de Arqueología Fenicio-Púnica (Eivissa 2007). Ibiza, Consellería d'Educació i Cultura, 9-24. Treballs del Museu Arqueologic d'Eivissa i Formentera 61.

Pérez de Perceval, M.A. (1984): Fundidores, mineros y comerciantes. La metalurgia de Sierra de Gádor, 1820-1850. Almería, Cajal.

Prados Martínez, F.; Blánquez Pérez, J. J. (2007): «Las fortificaciones coloniales en la Península Ibérica: de los modelos orientales a los sistemas púnico-helenísticos». L. Berrocal-Rangel; P. Moret (eds.): Paisajes fortificados de la Edad del Hierro. Las murallas protohistóricas de la Meseta y la vertiente atlántica en su contexto europeo. Madrid, Real Academia de la Historia-Casa de Velázquez, 57-80.

Ramón Torres, J. (1995): Las ánforas fenicio-púnicas del Mediterráneo central y occidental. Barcelona, Universitat de Barcelona.

Ramón Torres, J.; Sáez, A.; Sáez, A. M.; Muñoz, A. (2007): El taller alfarero tardoarcaico de Camposoto, (San Fernando, Cádiz). Sevilla, Consejería de Cultura.

R.A.P. (Red Andaluza de Posicionamiento) http:// www.juntadeandalucia.es/obraspublicasytransportes/redandaluzadeposicionamiento/rap/.

Ruiz Mata, D. (2001): «Arquitectura y urbanismo en la ciudad Protohistórica de Castillo de Doña Blanca (El Puerto de Santa María, Cádiz)». Ruiz Mata, D.; Celestino Pérez, S. (eds.): Arquitectura Oriental y Orientalizante en la Península Ibérica, 261274. Madrid.

Roldán Gómez, L.; Bendala, M.; Blánquez, J.; Martínez, S. (dirs.) (2006): Estudio histórico-arqueológico de la ciudad de Carteia (San Roque, Cádiz) 1994-1999. Sevilla, Consejería de Cultura.

Roldán Hervás, J.M. (ed.) (2006): Diccionario Akal de la Antigüedad hispana. Madrid, Akal.

Ruiz Mata, D.; Pérez, C. (1995): El poblado fenicio del Castillo de Doña Blanca (El Puerto de Santa María, Cádiz). El Puerto de Santa María, Ayuntamiento de El Puerto de Santa María.

Sala Sellés, F. (2006): «Les fortificacions a la Contestània: entre la representació social i la defesa del territori». A. Oliver Foix (coord.): Arquitectura defensiva. La protección de la población y del territorio en época ibérica. Castellón, Sociedad Castellonense de Cultura, 123-165.

Sánchez Hita, A. (2007): El camino de las fundiciones reales. Minería y fundición del plomo en el valle del Andarax y su entorno. Granada, A.D.R. Alpujarra-Sierra Nevada.

Schubart, H. (2000): «Alarcón. El yacimiento fenicio y las fortificaciones en la cima de Toscanos». A. González Prats (ed.): Fenicios y territorio, Actas del II Seminario Internacional sobre Temas Fenicios, Guardamar de Segura, 1999. Alicante, Instituto Juan Gil Albert, 263-294.

Suárez, A.; Carrilero, M.; García, J. L.; Bravo, A. (1985): «Memoria de la excavación de urgencia realizada en el yacimiento de Ciavieja (El Ejido, Almería), 1985». Anuario Arqueológico de Andalucía 1985, vol. III, 14-21.

Suárez, A.; Carrilero, M.; Mellado, C.; San Martín, C. (1986): «Memoria de la excavación de urgencia realizada en Ciavieja, El Ejido (Almería)». Anuario Arqueológico de Andalucía 1986, vol. III, 20-24.

Suárez, A.; López Castro, J. L.; Aguayo, P.; Carrilero, M.; San Martín, C. (1989): «Abdera. Una colonia fenicia en el sureste de la Península Ibérica». Madrider Mitteilungen 30, 135-150.

Untermann, J. (1990): Monumenta Linguarum Hispanicarum III: Die iberischen inschriften aus Spanien. Wiesbaden, Reichert.

Wright, G.R.H. (1985): Ancient building in South Syria and Palestine. Leiden-Köln, Brill.

Recibido el 17-06-09

Aceptado el 18-02-10 